Aus dem Institut für Anatomie und Embryologie

$$
\begin{gathered}
\text { (Prof. Dr. med. C. Viebahn) } \\
\text { im Zentrum Anatomie }
\end{gathered}
$$

der Medizinischen Fakultät der Universität Göttingen

\title{
Zur Bedeutung ungleichen Längenwachstums bei der Bildung der embryonalen Herzschleife - Untersuchungen an einem physikalischen Modell
}

\author{
Inaugural-Dissertation
}

zur Erlangung des Doktorgrades für Zahnheilkunde der Medizinischen Fakultät der Georg-August-Universität Göttingen

\author{
vorgelegt von \\ Meriç Bayraktar
}

aus

Istanbul, Türkei

Göttingen 2014 
Dekan: Prof. Dr. rer. nat. H. K. Kroemer

I. Berichterstatter: Priv.-Doz. Dr. med. J. Männer

II. Berichterstatter/in: Prof. Dr. med. T. Tirilomis

III. Berichterstatter/in: Prof. Dr. med. dent. R. Mausberg

Tag der mündlichen Prüfung: 28.09.2015 


\section{Inhaltsverzeichnis}

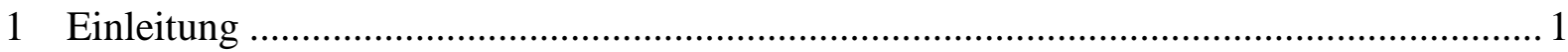

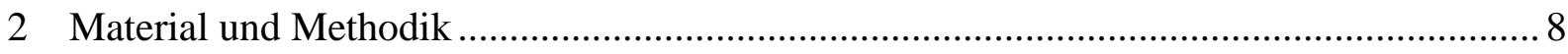

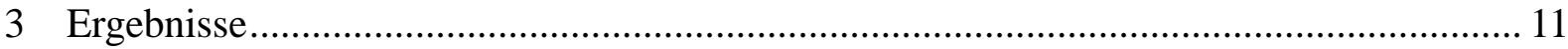

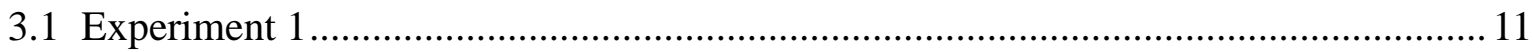

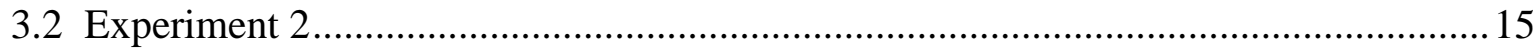

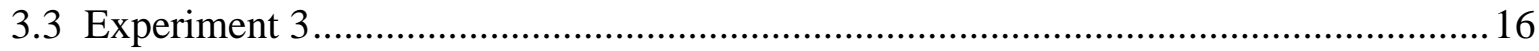

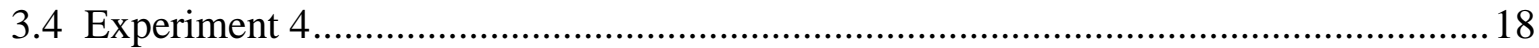

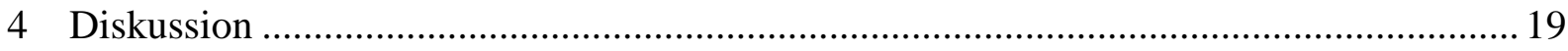

4.1 Zur Bedeutung ungleichen Wachstums für die Formbildung der embryonalen

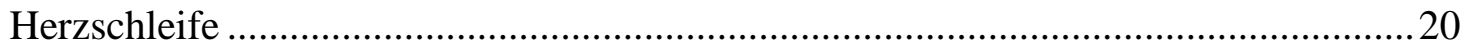

4.2 Zur Mechanik der ventralen Biegung der Herzschleife ............................................22

4.3 Zur Mechanik der schraubigen Verformungen der Herzschleife .................................23

4.4 Zur Mechanik der Determination der Händigkeit der Herzschleife .............................25

4.5 Zur mechanischen Stabilität der bei Bucklingprozessen erzeugten Deformationen ....28

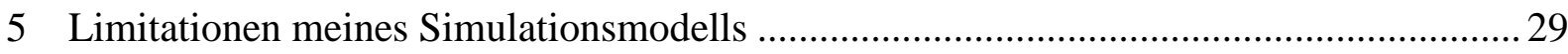

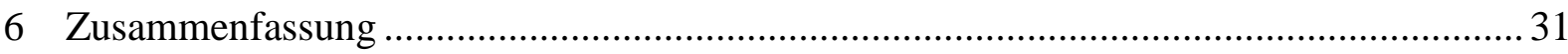

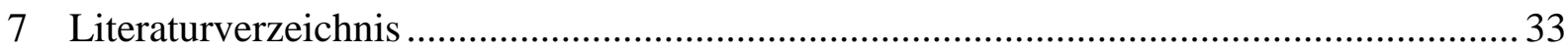




\section{Einleitung}

Bei Wirbeltierembryonen ist das Herz das erste Organ, das sich bildet und seine Funktion aufnimmt. Es entsteht aus der Vereinigung bilateral paariger Herzfelder ventral vom sich entwickelnden Vorderdarm. Während der initialen Phase der Vereinigung der Herzfelder erscheint das embryonale Herz als ein gerader, bilateral annähernd symmetrischer Schlauch, welcher entlang der ventralen Mittellinie des Vorderdarms ausgerichtet ist. Dieser Herzschlauch ist relativ kurz und besteht nur aus dem embryonalen linken Ventrikel. Er besitzt einen venösen Zufluss am caudalen Pol, über den er mit den sich entwickelnden Venen verbunden ist, und einen arteriellen Ausfluss am cranialen Pol, mit dem er mit dem Saccus aorticus und den Pharyngealbogenarterien verbunden ist. Seine dorsale Wand ist mit der dorsalen Wand der embryonalen Perikardhöhle über eine sagittale Gewebebrücke verbunden, die als dorsales Mesokard bezeichnet wird. Während der weiteren Vereinigung der Herzfelder wächst der Herzschlauch durch kontinuierliche Addition von Material an seinem venösen (Atrioventrikularkanal, einfaches Atrium, Sinus venosus) und arteriellen Pol (embryonaler rechter Ventrikel, proximale und distale Ausflussbahn). Die Verlängerung des Herzschlauchs geht einher (1.) mit dem Auflösen des dorsalen Mesokards, sodass der Herzschlauch nur noch am venösen (caudal) und arteriellen (cranial) Ende mit der Wand der embryonalen Perikardhöhle verbunden ist und (2.) mit auffälligen Veränderungen in der räumlichen Gestalt des sich entwickelnden Herzens, welches sich von einem geraden zu einem schraubig gewundenen Schlauch umformt.

Die Umformung eines initial geraden embryonalen Herzschlauchs zu einer schraubig gewundenen Herzschleife wird Cardiac looping genannt. Die Herzschleifenbildung wird als ein grundlegender Prozess in der Morphogenese des embryonalen Wirbeltierherzens angesehen, da durch ihn die zukünftigen Kammern und großen Gefäßstämme annähernd in ihre definitiven Lagebeziehungen gebracht werden.

Die Abfolge der dynamischen Formänderungen des Cardiac looping kann bei höheren Wirbeltieren in drei Phasen unterteilt werden (Männer 2000; Männer 2009): Während der ersten Phase biegt sich der initial gerade Herzschlauch nach ventral und vollzieht eine Torsion um die eigene Mittelachse. Infolgedessen nimmt er die Gestalt einer gegen den Uhrzeigersinn gewundenen, d. h. linkshändigen Helix an (Abb. 1). Diese Form erscheint bei einer zweidimensionalen Ansicht von vorn wie der lateinische Buchstabe „C“ und wird daher C-Loop genannt (Männer 2004). Die Konvexität dieses „C“ zeigt normalerweise zur rechten 
Seite des Embryos. Aufgrund dessen wird die erste Phase des Loopings auch Dextral looping genannt.

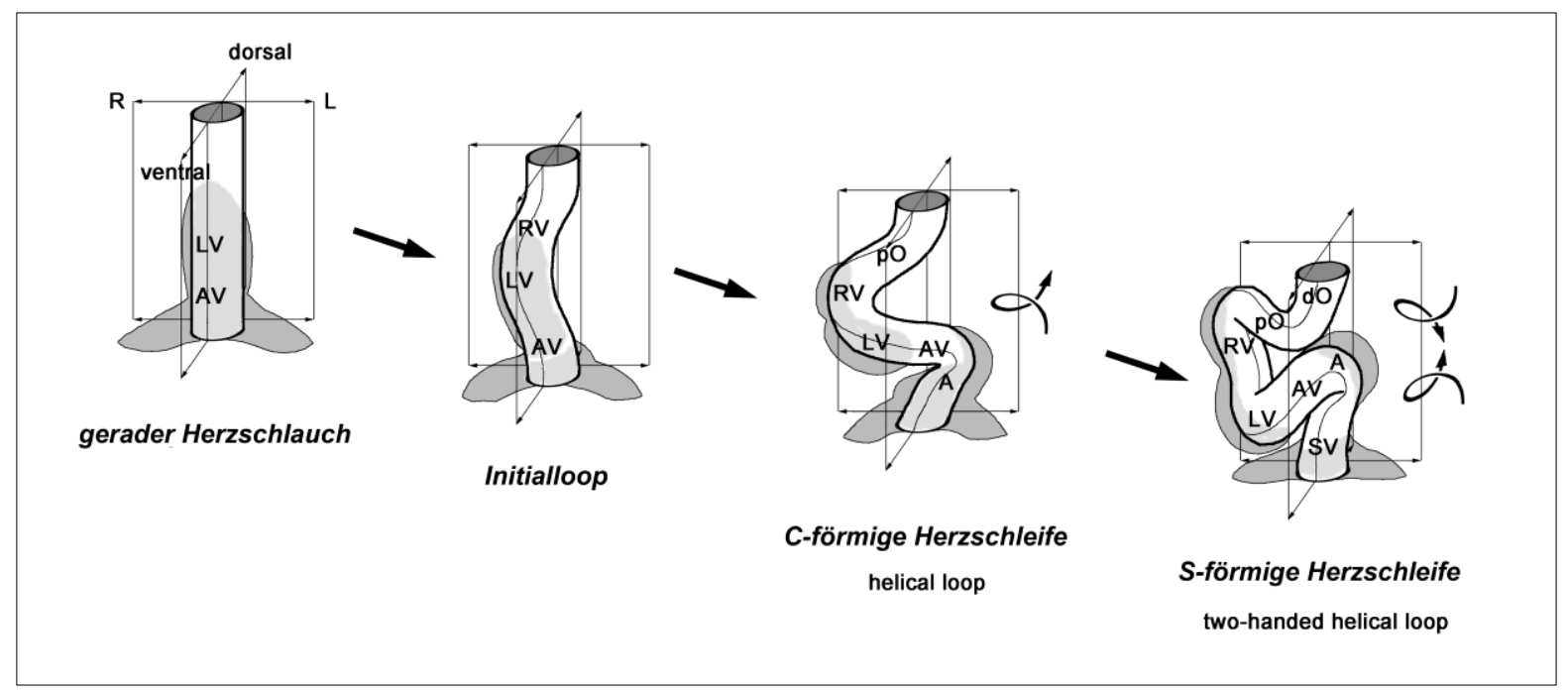

Abb. 1: Diese schematische Zeichnung veranschaulicht die Abfolge der idealisierten geometrischen Formänderungen, welche die Looping-Morphogenese des Herzschlauchs höherer Wirbeltierembryonen charakterisieren. Während der initialen Phase des Loopingprozesses beginnt sich der gerade Herzschlauch entlang der sagittalen Medianebene in Richtung der ventralen Körperwand zu biegen. Durch eine rechtsseitige Torsion verformt sich der gebogene Schlauch in eine gegen den Uhrzeigersinn gewundene Helix („C-Loop“). Abschließend nimmt die Herzschleife die komplexe Form einer zweihändigen Helix ein, welche aus einem caudalen Segment mit einer linkshändigen Windung und einem cranialen Segment mit einer rechtshändigen Windung besteht (,S-Loop“). A = Atrium; AV = Atrioventrikularkanal; LV = embryonaler linker Ventrikel; $\mathrm{dO}=$ distale Ausflussbahn; pO = proximale Ausflussbahn; RV = embryonaler rechter Ventrikel; SV = Sinus venosus. Abbildung aus Bayraktar und Männer (2014).

Während der zweiten Phase nimmt der Herzschlauch eine komplexe helikale Form ein, die üblicherweise S-Loop genannt wird, da sie bei einer zweidimensionalen Ansicht dem lateinischen Buchstaben „S“ ähnelt. Die komplexe räumliche Gestalt des S-Loops wurde kürzlich als helikale Perversion identifiziert (Männer 2013). Helikale Perversionen können in filamentären, schraubig gewundenen Objekten (z. B. Elektrokabel, Telefonschnüre) auftreten, wo sie zwei Segmente mit entgegengesetztem Windungssinn miteinander verbinden. Eine andere, deskriptivere Bezeichnung für ein solches Objekt wäre zweihändige Helix (Pieranski et al. 2004). Die räumliche Gestalt des sogenannten S-Loops höherer Wirbeltierembryonen entspricht einer entlang der cranio-caudalen Körperachse polarisierten zweihändigen Helix. Diese Helix besteht aus einem caudalen Segment mit einer linkshändigen Windung und einem cranialen Segment mit einer rechtshändigen Windung (Männer 2013). Beide Segmente sind mittels eines Loops verbunden, dessen Konvexität normalerweise nach rechts zeigt (Abb. 1). Entsprechend der Richtung des Blutflusses kann diese Herzschleife als LR-händige (links, rechts) Helix bezeichnet werden. Die dritte und abschließende Phase des Cardiac 
looping ist von Formänderungen gekennzeichnet, die man unter dem Begriff Untwisting zusammenfassen kann (Männer 2009).

Helices und polarisierte helikale Perversionen sind händige (chirale) Objekte. Dies bedeutet, dass sie prinzipiell in zwei Formvarianten, sogenannten Enantiomorphen, auftreten können. Jedes dieser Enantiomorphe ist das Spiegelbild des anderen (Männer 2013). In Bezug auf den embryonalen Herzschlauch hieße dies, dass der C-Loop und der S-Loop prinzipiell nicht nur in den oben beschriebenen helikalen Formvarianten (linkshändige Helix, LR-händige Helix) existieren können, sondern auch in spiegelbildlichen, enantiomorphen Formen (rechtshändige Helix, RL-händige Helix). Interessanterweise werden bei allen bisher untersuchten Wirbeltieren normalerweise nur die oben beschriebenen Enantiomorphe realisiert. Da die Konvexität des Kammeranteils dieser Herzschleifen nach rechts gerichtet ist, werden die biologisch normalen Enantiomorphe als D-Loop (dextral) bezeichnet, wohingegen die biologisch abnormen, spiegelbildlichen Enantiomorphe als L-Loop (levo) bezeichnet werden.

Seit dem 19. Jahrhundert fokussiert sich das Interesse am Phänomen des Cardiac looping auf zwei Fragen: (1.) Welche Faktoren führen zur Verbiegung und Torsion des embryonalen Herzschlauchs und (2.) welche Faktoren sind dafür verantwortlich, dass bei allen bisher untersuchten Wirbeltieren während der Embryogenese normalerweise nur das D-LoopEnantiomorph realisiert wird?

Während der letzten zwei Jahrzehnte gab es erhebliche Fortschritte bei der Beantwortung dieser Fragen. So wurde eine Vielzahl an Genen und molekularen Signalkaskaden identifiziert, welche wichtige Rollen spielen: entweder (1.) beim Längenwachstum, der Biegung und der Torsion des Herzschlauchs oder (2.) bei der Determination der Händigkeit des Loops. Dies legt nahe, dass diese beiden Aspekte des Cardiac looping von unterschiedlichen Faktoren gesteuert werden (Männer 2013). Die Frage, wie diese genetischen Informationen und molekularen Signale in mechanische Kräfte übersetzt werden, welche die dynamischen Formänderungen des Herzschlauchs bewirken, ist noch immer offen.

Die historisch älteste und populärste Vorstellung über die Biomechanik des Cardiac looping besagt, dass die Biegung und die Torsion des embryonalen Herzschlauchs darauf zurückzuführen sind, dass sein Längenwachstum durch die ihn umgebende Perikardhöhle mechanisch behindert wird (His 1868; Goette 1875; Tandler 1912; Robertson 1914; Patten 1922; Davis 1927; Bremer 1928; Fransen und Lemanski 1988). Diese Hypothese beruht vor 
allem auf der Beobachtung, dass der Herzschlauch während des Loopings rasant an Länge zunimmt, wohingegen der Abstand zwischen seinem venösen und seinem arteriellen Ende relativ konstant bleibt (Abb. 2).

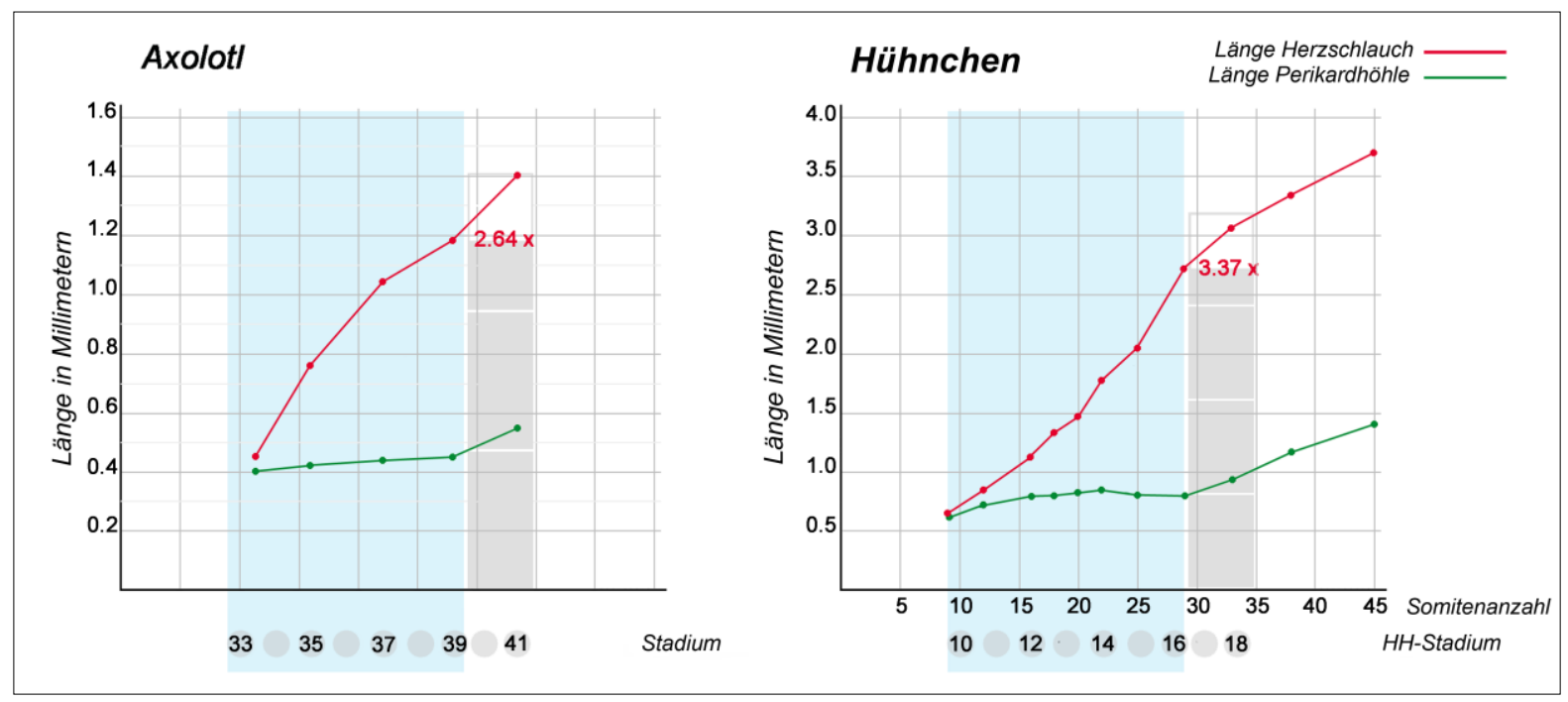

Abb. 2: Diese Diagramme zeigen das Längenwachstum des embryonalen Herzschlauchs während des Loopingprozesses im Vergleich zum cranio-caudalen Wachstum der Perikardhöhle. Die Diagramme beruhen auf Daten von Axolotl- (Fransen und Lemanski 1988) und Hühnerembryonen (Patten 1922). Während der Phase des dextralen und des frühen S-Loopings (blau markiert) bleibt die cranio-caudale Länge der Perikardhöhle relativ konstant, während der Herzschlauch erheblich an Länge zunimmt. Zu Beginn des Loopingprozesses entspricht die Länge des Herzschlauchs derjenigen der Perikardhöhle. Am Ende des frühen SLoopings jedoch ist die Herzschleife von Axolotlembryonen 2,64-mal so lang und die Herzschleife von Hühnerembryonen 3,37-mal so lang wie deren Perikardhöhlen. Abbildung aus Bayraktar und Männer (2014).

Sollte diese Hypothese zutreffen, würde das biologische Phänomen der Herzschleifenbildung einem aus der Bohrindustrie bekannten technischen Phänomen entsprechen, das im Englischen als Buckling bezeichnet wird. Der Begriff kennzeichnet Deformationen (z. B. Knickungen, Biegungen, Torsionen) von Objekten (z. B. Pfeiler, Säulen) als Folge von Druckbelastungen. Ein gerades Bohrgestänge verformt sich innerhalb eines Bohrlochs, wenn es einer axialen Druckbelastung ausgesetzt wird, die einen kritischen Wert übersteigt, bis zu dem die gerade Form noch stabil ist. Oberhalb dieses Wertes nimmt das Bohrgestänge zunächst gebogene (sinusoidale) und später schraubige (helikale) Konformationen an (Tan und Forsman 1995). Im Falle des embryonalen Herzschlauchs dürfte eine axiale Druckbelastung durch die kontinuierliche Addition von neuem, aus den Herzfeldern stammendem Material sowohl am arteriellen als auch am venösen Ende hervorgerufen werden. Demnach scheint es sinnvoll, die historisch älteste Hypothese der Mechanik des Cardiac looping als wachstumsbedingtes Buckling zu bezeichnen. 
Für viele Jahre war die Buckling-Hypothese aus dem Fokus der aktuellen embryologischen Forschung geraten, da es schien, sie sei durch experimentelle Daten widerlegt worden. So wurde berichtet, dass embryonale Herzschläuche auch dann ein Looping durchlaufen, wenn sie aus der embryonalen Perikardhöhle explantiert und in vitro, d. h. ohne räumliche Begrenzung, kultiviert werden (Ekman 1925; Bacon 1945; Butler 1952; Manning und McLachlan 1990). Es zeigte sich allerdings, dass dieses In-vitro-Looping einfacher abläuft als das normale In-situ-Looping, da Ersteres zu Herzschleifen führt, die lediglich in einer Ebene gebogen sind (planares Looping) und keine schraubige Verformung zeigen (räumliches Looping) (Flynn et al. 1991; Latacha et al. 2005; Rémond et al. 2006; Ramasubramanian et al. 2013). Aus diesem Grund schreiben derzeitige Hypothesen zur Mechanik des Cardiac looping das Biegen des embryonalen Herzschlauchs Faktoren zu, die innerhalb des Myokards liegen (Latacha 2005; Taber 2006; Taber et al. 2010), während die Deformation in eine helikale Form primär außerhalb des Herzens liegenden Faktoren zugeschrieben wird (Taber 2006; Taber et al. 2010; Männer 2013). Jüngste Experimente an Hühnerembryonen haben gezeigt, dass durch die ventrale Wand der primären Perikardhöhle ein mechanischer Druck auf den sich biegenden Herzschlauch ausgeübt wird, ohne den es nicht zur Torsion der Herzschleife kommt (Taber 2006; Taber et al. 2010; Voronov und Taber 2002; Filas et al. 2007). Dieser Befund legt nahe, dass die Größe und die Geometrie der embryonalen Perikardhöhle wichtige extrinsische Determinanten des Cardiac looping sind. Dieser Befund zeigt weiterhin, dass man die Buckling-Hypothese nicht länger ignorieren sollte, wenn man einen umfassenden Einblick in die Biomechanik des Cardiac looping erhalten will.

Angesichts der oben erwähnten neuen Befunde wollten wir herausfinden, welche Rolle wachstumsbedingtes Buckling beim Cardiac looping spielen könnte. Als ersten Schritt auf diesem Weg erforschten wir, ob die für das Cardiac looping typische Abfolge von Formänderungen des Herzschlauchs (Abb. 1) mit der Abfolge von Formänderungen übereinstimmt, die beim Buckling eines elastischen Schlauchs oder Stabs innerhalb eines begrenzenden Raumes auftritt. Zu unserer Überraschung fanden wir heraus, dass diese Frage in embryologischen Studien der letzten 200 Jahre nicht bearbeitet worden war. Daher suchten wir nach einer Antwort in der ingenieurswissenschaftlichen Literatur, die sich mit dem technischen Problem des Bucklings von Bohrgestängen beschäftigt (siehe oben). Labortests haben gezeigt, dass dieser Prozess in zwei aufeinanderfolgenden Schritten abläuft (Tan und Forsman 1995): Wenn ein langes Bohrgestänge einer stetig wachsenden axialen Kompression ausgesetzt wird, biegt es sich zunächst entlang einer Ebene (planares, zweidimensionales oder sinusoidales Buckling), bis die Gipfel der Biegungen die Wand des Bohrloches berühren. 
Bei weiter zunehmender Kompression verformt sich das Bohrgestänge nun auf eine dreidimensionale Art und Weise und nimmt die Form einer Helix an (räumliches oder helikales Buckling). Ein solches Formverhalten würde dem des embryonalen Herzens während der ersten Phase des Cardiac looping (dextrales oder C-Looping) entsprechen und daher im Einklang mit der Idee stehen, dass die helikale Gestalt des C-Loops durch wachstumsbedingtes Buckling verursacht wird.

Leider konnten wir keine Antwort auf die Frage finden, ob beim räumlichen Buckling eines Bohrgestänges auch die komplexe Form einer zweihändigen Helix entstehen kann, welche die idealisierte geometrische Form des sogenannten S-Loops darstellt. Deshalb entschieden wir uns, eine mechanische Apparatur zu konstruieren, die als physikalisches Looping-Modell dienen sollte. Mit diesem Modell wollten wir testen, ob wachstumsbedingtes Buckling eines geraden elastischen Stabs (Modell für den embryonalen Herzschlauch) innerhalb einer hohlen Halbkugel (Modell für die embryonale Perikardhöhle) eine Abfolge von Formänderungen erzeugen kann, die derjenigen beim Cardiac looping entspricht (gerader Schlauch $\rightarrow$ sinusoidaler Loop $\rightarrow$ helikaler Loop $\rightarrow$ zweihändiger helikaler Loop).

Würde das reale oder simulierte Cardiac looping unter Bedingungen mit exakter bilateraler Symmetrie ablaufen, wäre zu erwarten, dass die resultierenden Loop-Enantiomorphe (D-Loop und L-Loop) in einem ausgeglichenen Zahlenverhältnis (1:1) auftreten. Daher wird vermutet, dass die biologisch normale, annähernd 100\%ige Präferenz für das D-Loop-Enantiomorph (siehe oben) von funktionellen oder strukturellen Asymmetrien verursacht wird, die bereits vor dem Cardiac looping im Embryo vorhanden sind (Stalsberg 1970). Studien an Mäusen, Katzen und menschlichen Embryonen haben gezeigt, dass das venöse Ende des geraden Herzschlauchs (der spätere Atrioventrikularkanal) bereits kurz vor dem Beginn des Loopingprozesses ein wenig nach links verlagert wird (Schulte 1916; De Vries und Saunders 1962; Biben und Harvey 1992), und einige Autoren haben vermutet, dass diese Asymmetrie entscheidend für die Determination des D-Loop-Phänotyps ist (von Baer 1828, Schulte 1916, Biben und Harvey 1992). 


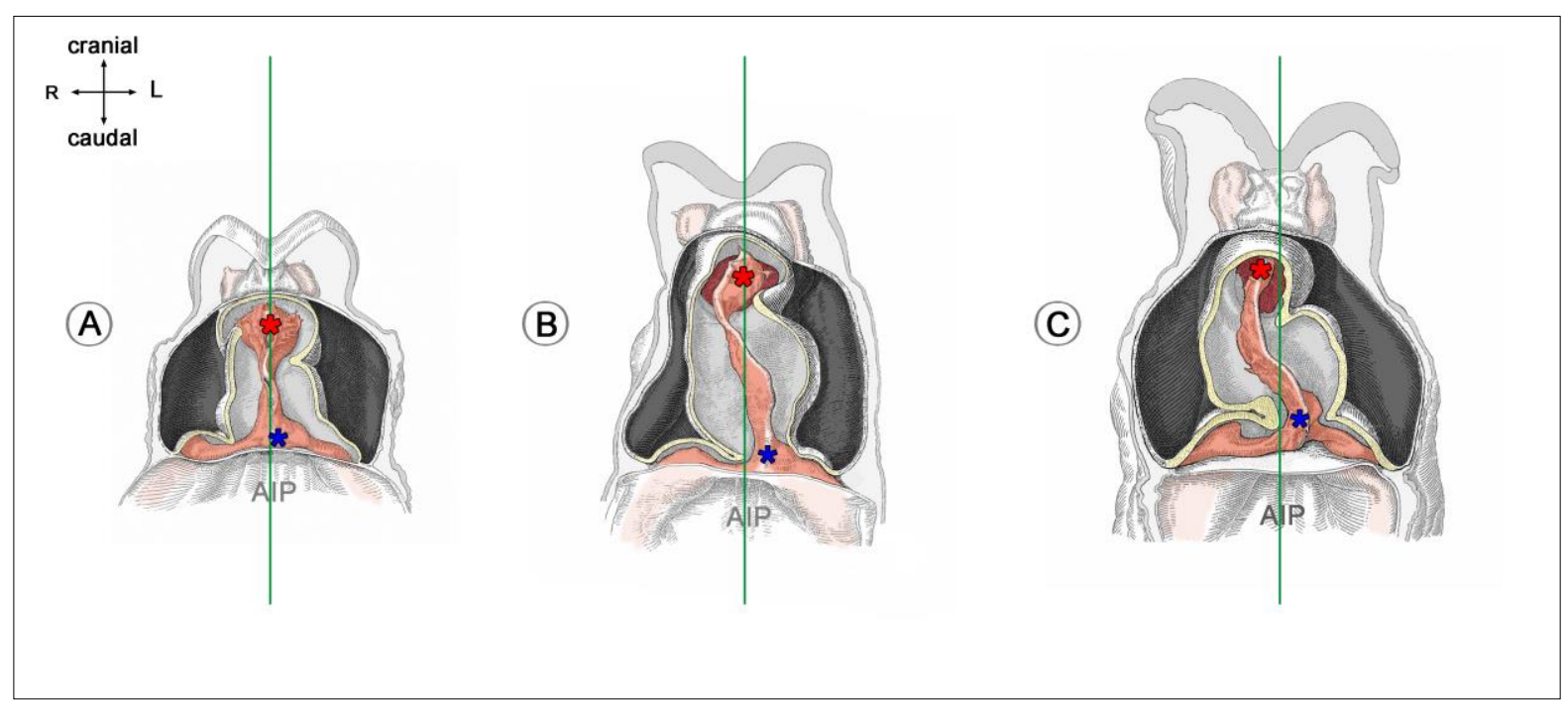

Abb. 3: Diese Zeichnungen zeigen die asymmetrische Positionierung des venösen Pols von menschlichen embryonalen Herzschläuchen vor (A) und während der initialen Phase des Cardiac looping (B, C). Die Herzen sind in Frontalansicht innerhalb der geöffneten Perikardhöhle dargestellt. Die ventralen Herzmuskelwände wurden entfernt, um die Sicht auf die Endokardschläuche zu ermöglichen. A: Vor Beginn des Loopingprozesses ist die Zentralachse des venösen Herzpols (blaues Sternchen) leicht aus der sagittalen Medianebene (grüne Linie) nach links versetzt. B, C: Das Ausmaß der Linksverschiebung des venösen Pols nimmt während der initialen Phase des Loopingprozesses zu. Zu beachten ist auch, dass der arterielle Pol eine Rechtsverschiebung vollzieht. Die Zeichnungen basieren auf den Abbildungen 18, 20 und 22 von Davis (1927). AIP = vordere Darmpforte (anterior intestinal portal). Abbildung aus Bayraktar und Männer (2014).

Im Zusammenhang mit der Buckling-Hypothese scheint diese Spekulation Sinn zu ergeben, da zu erwarten ist, dass eine Linksverschiebung des venösen Herzendes zu einer bilateral asymmetrischen Verteilung der axialen Last innerhalb des Herzschlauchs führt. Diese asymmetrische Krafteinwirkung könnte den Prozess des Bucklings in eine statistisch nicht randomisierte Richtung lenken. Daher haben wir uns entschlossen, das oben genannte Modell zur Simulation des Cardiac looping so zu konstruieren, dass es uns ermöglicht, das Bucklingverhalten eines elastischen Stabs unter zwei verschiedenen Bedingungen zu untersuchen: (1.) bilaterale Symmetrie und (2.) bilaterale Asymmetrie, die durch Verlagerung des caudalen Endes vor der Durchführung des Tests hervorgerufen wird.

In der vorliegenden Studie habe ich dieses Modell genutzt, um drei Fragen zu beantworten: (1.) Kann wachstumbedingtes Buckling eines elastischen, geraden Stabs in einer engen hohlen Halbkugel die gleiche Abfolge von Formänderungen verursachen, wie sie beim Cardiac looping beobachtet worden ist? (2.) Kann eine Linksverschiebung des caudalen Endes eines elastischen Stabs den Bucklingprozess in eine Richtung lenken, welche die Bildung einer helikalen Form begünstigt, die dem D-Loop-Enantiomorph entspricht; und kann eine Rechtsverschiebung des caudalen Endes den Bucklingprozess in eine Richtung lenken, welche die Bildung einer helikalen Form begünstigt, die dem L-Loop-Enantiomorph 
entspricht? (3.) Können bereits geringfügige Links- oder Rechtsverschiebungen des caudalen

Endes den Bucklingprozess in Richtungen lenken, bei denen D-Loop- oder L-LoopEnantiomorphe in $100 \%$ der Fälle auftreten?

\section{Material und Methodik}

Das physikalische Simulationsmodell ist in Abb. 4 gezeigt. Sämtliche Komponenten des Modells sind auf einer horizontal gelagerten Holzplatte befestigt. Eine aus transparentem Plastik bestehende hohle Halbkugel mit einem Innendurchmesser von 136 mm repräsentiert die ventro-laterale Wand der Perikardhöhle. Diese Halbkugel ist auf einem planen Tisch angebracht, der die dorsale Wand der Perikardhöhle darstellt. In die seitliche Wand der Modell-Perikardhöhle wurden zwei sich gegenüberliegende Öffnungen geschnitten, die in der cranio-caudalen Achse des Modells liegen. Diese Öffnungen repräsentieren das craniale (arterielle) und das caudale (venöse) Ende der Perikardhöhle. Im Verlauf der Versuchsbeschreibung werden analog dazu die Bezeichnungen „cranial“ und „caudal“ in Bezug auf die Längsachse des Modells verwendet.
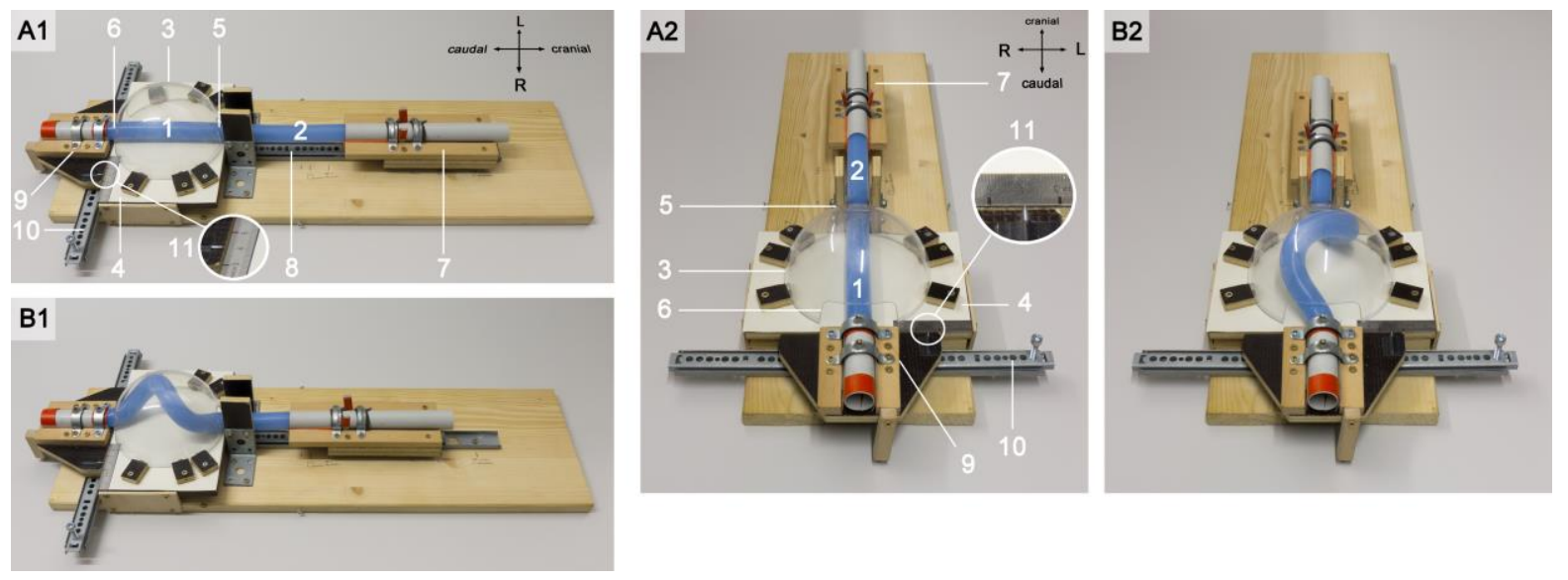

Abb. 4: Diese Fotos dokumentieren das Design des physikalischen Simulationsmodells. Das Modell ist in zwei verschiedenen Ansichten dargestellt, die es jeweils vor (A1, A2) und während (B1, B2) eines Bucklingversuches zeigen. Die Zahlen bezeichnen folgende Komponenten: $1=$,intra-perikardialer“ Anteil des Silikonstabs; 2 = „extra-perikardialer“ Anteil des Silikonstabs; 3 = hohle Halbkugel aus transparentem Hartkunststoff, welche die ventro-lateralen Wände der Perikardhöhle repräsentiert; 4 = flache Ebene/Bühne, welche die dorsale Wand der Perikardhöhle repräsentiert; 5 = Öffnung am cranialen (arteriellen) Pol der „Perikardhöhle“; 6 = Öffnung am caudalen (venösen) Pol der „Perikardhöhle“; 7 = cranialer Schlitten, der das craniale Ende des Silikonstabs trägt; 8 = kugelgelagerte Laufschiene für eine exakte Verschiebung des cranialen Schlittens entlang der cranio-caudalen Achse; 9 = caudaler Schlitten, der das caudale Ende des Silikonstabs trägt; 10 = kugelgelagerte Laufschiene für eine genaue Verschiebung des caudalen Schlittens entlang der Links-rechtsAchse; 11 = Messskala für eine genaue Positionierung der Mittelachse des caudalen Endes des Silikonstabs entlang der Links-rechts-Achse (die Mittellinie entspricht der Linie 4 der Messskala; die Mittelachse des caudalen Endes des Silikonstabs ist mit einem Metallnagel auf dem caudalen Schlitten markiert). Abbildung aus Bayraktar und Männer (2014). 
Für die Bucklingtests wurde als Modell des wachsenden Herzens ein eigens für den Versuchsaufbau hergestellter elastischer Silikonstab mit einer Gesamtlänge von $480 \mathrm{~mm}$ und einem Durchmesser von $23 \mathrm{~mm}$ verwendet. Dieser Silikonstab wurde aus einem handelsüblichen additionsvernetzten Zweikomponenten-Silikon gegossen (Thiesasil 17 ®, Thie und Söhne, Deutschland; Komponente A: Polysiloxane und Füller, Komponente B: Härter, Verhältnis A/B = 10:1). Das gummielastische Polymer weist nach der Shore-A-Skala eine Härte von 17 auf und kann daher als weich und elastisch klassifiziert werden. Verglichen mit echten embryonalen Herzschleifen ist es jedoch ein relativ steifes Objekt. Demnach entsprechen die Materialeigenschaften unseres Herzschlauchmodells nicht denen echter embryonaler Herzschleifen. Ein Silikonstab der Shore-Härte 17 ist jedoch als das am besten geeignete Material für unser Herzschlauchmodell gewählt worden, weil seine Materialeigenschaften (1.) höchstmögliche Verformbarkeit mit (2.) kompletter Reversibilität der durch Buckling verursachten Derformationen kombinieren (elastische Deformation). Diese mechanischen Eigenschaften minimieren das Risiko eines durch plastische Deformation bedingten verfälschenden Memory-Effekts bei wiederholten Bucklingtests. Anzumerken ist, dass der Silikonstab kein Lumen hat. Dies bedeutet, dass mein Modell den tubulären Bau der Herzschleife vernachlässigt. Ich gehe jedoch davon aus, dass dieser Sachverhalt die Aussagekraft meines Simulationsmodells nicht signifikant beeinflusst, da das frühe embryonale Herz ein dickwandiges Blutgefäß ist, das nur ein dünnes, schlitzförmiges Lumen besitzt, das während der Kontraktion durch seine myokardiale Wand komplett geschlossen ist (Männer et al. 2008).

Der gerade Silikonstab ist entlang der cranio-caudalen Achse des Modells ausgerichtet. In geradem Zustand sind $136 \mathrm{~mm}$ des Silikonstabs innerhalb der „Perikardhöhle“, während sich die restlichen $\sim 344 \mathrm{~mm}$ außerhalb derselben befinden. Demnach unterscheiden wir zwischen zwei Abschnitten des Stabs: (1.) einem „intra-perikardialen“ Abschnitt, der den embryonalen Herzschlauch darstellt und (2.) einem ,extra-perikardialen“ Abschnitt, der die Herzfelder darstellt, aus welchen neues Material dem Herzen hinzugefügt wird. Das craniale Ende des Silikonstabs ist mit einem Plastikrohr versteift und mit Halbmanschetten auf einem Schlitten befestigt. Dieser Schlitten ist mit einer geraden, kugelgelagerten Schiene verschraubt, die auf der Mittellinie des Modells montiert ist. Dies ermöglicht eine exakte Verschiebung des cranialen Anteils des Silikonstabs entlang der cranio-caudalen Achse. Das caudale Ende des Stabs ist ebenfalls mit einem Plastikrohr versteift und mit Halbmanschetten auf einem zweiten Schlitten befestigt. Auch dieser Schlitten ist mit einer geraden, kugelgelagerten Schiene verschraubt, die senkrecht zur cranio-caudalen Achse verläuft. 
Dies ermöglicht eine exakte Verschiebung des caudalen Pols des Silikonstabs entlang der Links-rechts-Achse. Während des Pre-Loop-Stadiums (gerader Herzschlauch) beträgt das Verhältnis der Länge zum Durchmesser des Herzschlauchmodells 5,91:1 (136 mm / 23 mm). Dieser Wert ist höher als der entsprechende Wert bei Wirbeltieren (z. B. Huhn 3,94, Mensch 2,63, Krallenfrosch 1,85; eigene Messungen anhand von Abbildungen). Das bedeutet, dass unser Herzschlauchmodell dünner ist als ein realer embryonaler Herzschlauch. Das schlanke Design ist in der Materialeigenschaft des Silikonstabs begründet, welcher steifer ist als der embryonale Herzschlauch (siehe oben). Folglich setzt der verringerte Durchmesser die für die Formänderungen benötigte axiale Kompressionslast auf den Silikonstab herab.

Für die Simulation des cranio-caudalen Wachstums des Herzschlauchs wurde der Schlitten, der das craniale Ende des Silikonstabs trägt, entlang der cranio-caudalen Achse in Richtung des caudalen Pols verschoben (Abb. 4 B1, B2). Eine bilateral symmetrische (Mittellinie) oder asymmetrische (links- oder rechtsseitig) Position des „venösen Herzpols“ erreicht man, indem man den Schlitten des caudalen Endes des Stabs verschiebt. Um einen die Ergebnisse verfälschenden Formgedächtniseffekt $\mathrm{zu}$ vermeiden, wurden die Bucklingtests in asymmetrischen Positionen (links- oder rechtsseitig) des „,venösen Herzpols“ alternierend durchgeführt.

Anzumerken ist noch, dass mein Loopingmodell das cranio-caudale Wachstum der Herzschleife nur durch Addition von Material am cranialen Herzende simuliert. Infolgedessen wird die axiale Druckkraft nur auf das craniale Ende des Silikonstabs ausgeübt. Das unterscheidet sich von der In-vivo-Situation, bei der der Herzschlauch durch Addition von Material sowohl am cranialen als auch am caudalen Ende verlängert wird (van den Berg et al. 2009, Kelly 2012). Aus physikalischer Sicht macht es jedoch keinen Unterschied, ob die axiale Druckkraft nur auf ein oder auf beide Enden des Stabs ausgeübt wird. Die Beschränkung der Wachstumssimulation auf den cranialen Pol des Modells erleichterte die Konstruktion des caudalen Pols, mit dem nun lediglich Links- bzw. Rechtsverschiebungen des venösen Herzpols simuliert werden mussten. Demnach wurde das vorliegende Konstruktionsprinzip gewählt, da es die Handhabung meines Modells erheblich vereinfachte.

Haftreibung hat einen großen Einfluss auf die Geometrie der Bucklingkonfiguration (Tan und Forsman 1995). Um die Haftreibung zwischen dem Silikonstab und der Wand der „Perikardhöhle“ zu reduzieren, wurde die Oberfläche des Silikonstabs mit einem Polymethylmethacrylat-Puder bestrichen (Paladon ${ }^{\circledR} 65$; Heraeus Kulzer GmbH, Deutschland, 
Partikelgröße 40-160 $\mu \mathrm{m}$ ).

Bei dem oben beschriebenen Aufbau des Modells war zu erwarten, dass das sinusoidale Buckling (planare Krümmung) des ,intra-perikardialen“ Teils des Silikonstabs nicht entlang einer favorisierten Ebene verlaufen würde. Das unterscheidet sich vom realen Cardiac looping, bei dem der Krümmungsprozess stets gegen die ventrale Wand der Perikardhöhle gerichtet ist. Um das sinusoidale Buckling des ,intra-perikardialen“ Teils des Silikonstabs gegen die ventrale Wand der „Perikardhöhle“ zu richten, wurde die Mittelachse des cranialen und des caudalen Endes in Bezug auf die Mitte der Perikardhöhle leicht nach ventral geneigt. Diese diskreten Abweichungen der Mittelachse des Silikonstabs von der cranio-caudalen Achse des Gesamtmodells entsprechen den Verhältnissen des geraden Herzschlauchs bei menschlichen Embryonen mit 7 Somiten (siehe Abb. 4 in De Vries und Saunders 1962).

Sämtliche Experimente wurden bei einer konstanten Raumtemperatur von $25^{\circ} \mathrm{C}$ durchgeführt. Um die Deformationen des Silikonstabs während der Bucklingexperimente zu dokumentieren, wurden Fotos aus standardisierten Ansichten (frontal, rechts lateral, links lateral) aufgenommen.

\section{Ergebnisse}

\subsection{Experiment 1}

Die erste Serie von Bucklingtests wurde durchgeführt, um herauszufinden, ob durch Längenwachstum verursachtes Buckling eines initial geraden Silikonstabs (stellvertretend für den embryonalen Herzschlauch) innerhalb einer engen halbkugeligen Höhle (stellvertretend für die Perikardhöhle) die gleiche Abfolge von Deformationen generiert, die auch beim Looping eines embryonalen Herzschlauchs zu beobachten ist. Diese Tests wurden unter bilateral symmetrischen Bedingungen durchgeführt (die Mitten der beiden Enden des Silikonstabs befanden sich auf der Mittellinie der cranio-caudalen Achse).

Zur Simulation des Längenwachstums des Herzschlauchs wurde das craniale Ende des Silikonstabs entlang der cranio-caudalen Achse in Richtung des caudalen Pols verschoben. Hierbei wurde der Silikonstab einer kontinuierlich zunehmenden axialen Kompression ausgesetzt und ursprünglich „extra-perikardiale“ Anteile des Silikonstabs 
wurden in die „Perikardhöhle“ verlagert. Infolgedessen nahm der ,intra-perikardiale“ Anteil des Silikonstabs an Länge zu und begann, sich in einer Ebene zu verbiegen (sinusoidales Buckling; Abb. 5A, B).
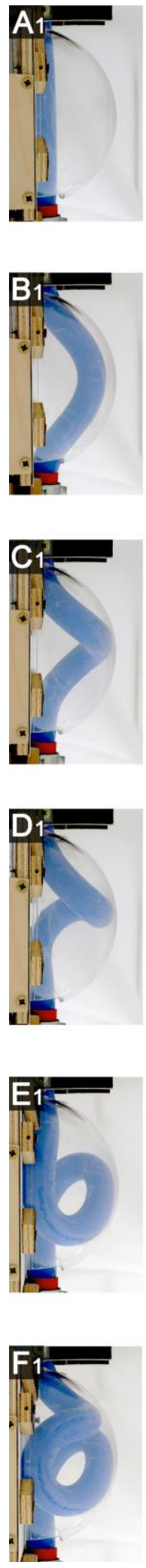
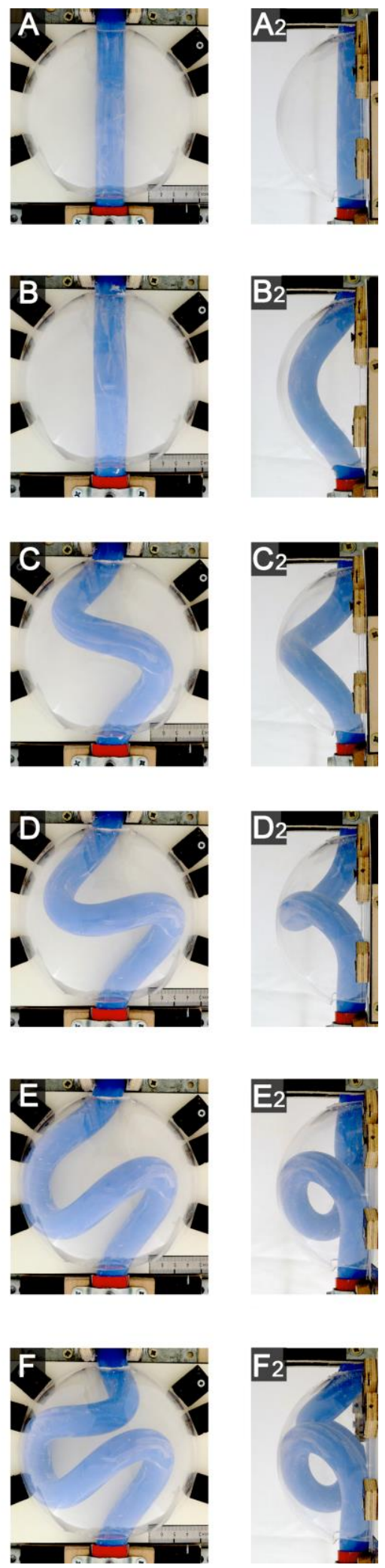

Abb. 5: Diese aus frontaler (A-F), rechtslateraler (A1-F1) und links-lateraler (A2-F2) Ansicht aufgenommenen Fotos dokumentieren die Formänderungen des sich kontinuierlich verlängernden ,intra-perikardialen“ Anteils des Silikonstabs während des ersten Bucklingversuchs. A, A1, A2: Gerader Silikonstab. B, B1, B2: Sinusoidales Buckling entlang der sagittalen Medianebene. C, C1, C2 bis E, E1, E2: Simples helikales Buckling (hier: linkshändige Helix). F, F1, F2: Komplexes helikales Buckling = Umformung einer einhändigen Helix zu einer zweihändigen Helix (hier: linkshändige Helix $\rightarrow$ LR-Helix). Vergleiche die durch Buckling erzeugten Deformationen mit den in Abb. 1 gezeigten idealisierten Formen der Herzschleife. Abbildung aus Bayraktar und Männer (2014). 
Da die Mittelachse des cranialen und des caudalen Endes des „,intra-perikardialen“ Anteils des Silikonstabs gegen die Mitte der ventralen Wand der „Perikardhöhle“ gerichtet war (siehe Material und Methoden), richtete sich der Krümmungsprozess regelmäßig ebenfalls dorthin und war auf eine Ebene begrenzt, die der sagittalen Medianebene des Wirbeltierkörpers entspricht. Nachdem die Konvexität des sich krümmenden Silikonstabs in Berührung mit der ventralen Wand der „Perikardhöhle“ kam, wandelte sich der zweidimensionale (sinusoidales Buckling) in einen dreidimensionalen Krümmungsprozess um, wobei der Silikonstab zunächst die Form einer einfach gewundenen Helix annahm (simples helikales Buckling; Abb. 5C). Bei wiederholten Tests $(n=50)$ traten links- und rechtshändige Helices nahezu im gleichen Zahlenverhältnis auf (Tabelle 1; Abb. 6).

\begin{tabular}{|rr|r|r|}
\cline { 3 - 4 } & & $\begin{array}{c}\text { Linkshändige Helix } \\
\text { D-Loop-Enantiomorph }\end{array}$ & $\begin{array}{c}\text { Rechtshändige Helix } \\
\text { L-Loop-Enantiomorph }\end{array}$ \\
\hline Mittellinienposition & $\mathrm{n}=50$ & $28(56 \%)$ & $22(44 \%)$ \\
\hline Linksverschiebung & $1 \mathrm{~mm}(\mathrm{n}=50)$ & $47(94 \%)$ & $3(6 \%)$ \\
& $2 \mathrm{~mm}(\mathrm{n}=50)$ & $50(100 \%)$ & - \\
$5 \mathrm{~mm}(\mathrm{n}=50)$ & $50(100 \%)$ & - \\
& $10 \mathrm{~mm}(\mathrm{n}=50)$ & $50(100 \%)$ & $50(100 \%)$ \\
\hline Rechtsverschiebung & $1 \mathrm{~mm}(\mathrm{n}=50)$ & - & $50(100 \%)$ \\
& $2 \mathrm{~mm}(\mathrm{n}=50)$ & - & $50(100 \%)$ \\
$5 \mathrm{~mm}(\mathrm{n}=50)$ & - & $50(100 \%)$ \\
\hline
\end{tabular}

Tabelle 1: Beziehung zwischen der Position des caudalen Endes des Silikonstabs vor Beginn des Bucklingprozesses und der Händigkeit des helikalen Bucklings. Tabelle aus Bayraktar und Männer (2014). 


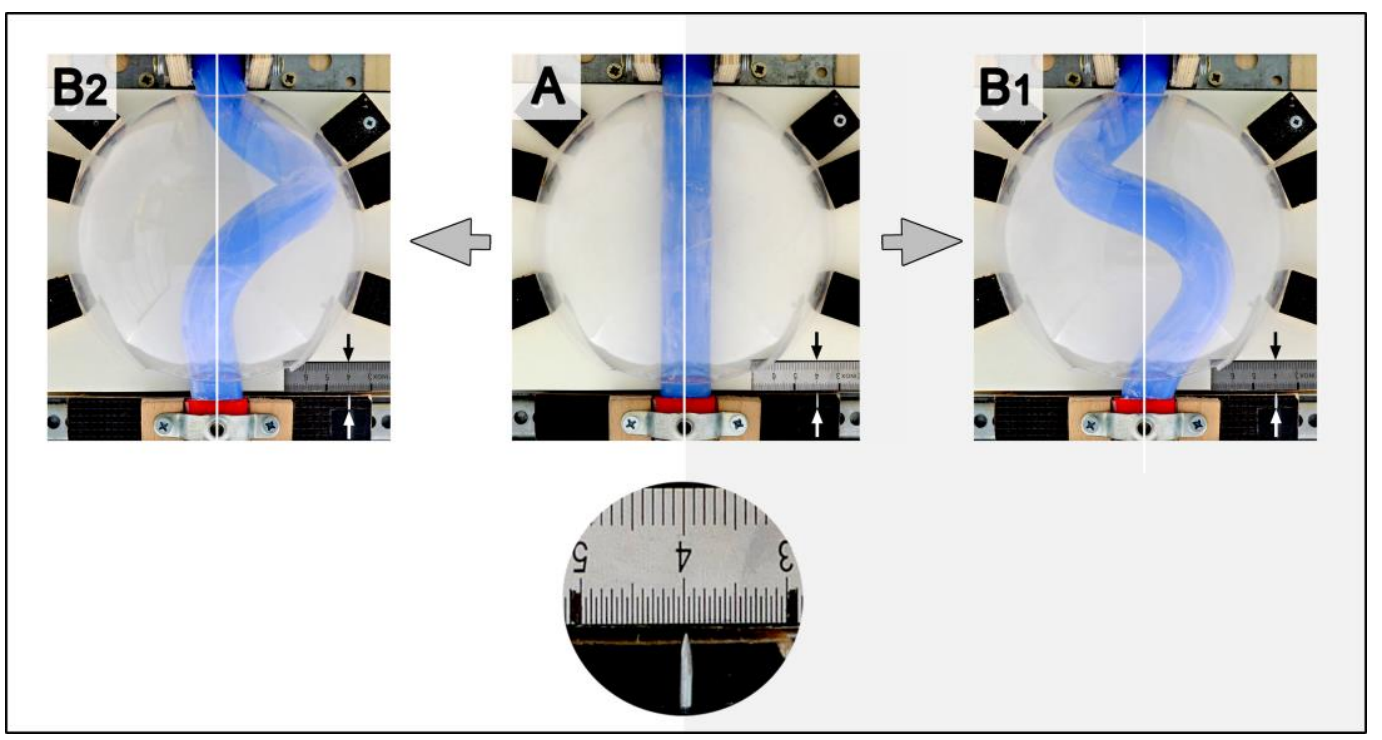

Abb. 6: Diese Fotos (Frontalansichten) zeigen, dass das helikale Buckling unter bilateral symmetrischen Bedingungen sowohl links- als auch rechtshändige Helices erzeugte. A: Der „intra-perikardiale“ Anteil des Silikonstabs vor Beginn des Bucklingversuchs. Beachte die Mittellinienposition der Zentralachse des geraden Silikonstabs [die Mittellinie ist durch eine weiße Linie und die Linie 4 auf der Messskala gekennzeichnet (schwarzer Pfeil)]. B1, B2: Der „intra-perikardiale“ Anteil des Silikonstabs während des helikalen Bucklings. Die Fotos zeigen eine linkshändige Helix (B1) und eine rechtshändige Helix (B2). Beachte, dass die Mittelachsen des cranialen und des caudalen Endes des Silikonstabs an ihren ursprünglichen Mittelinienpositionen verbleiben. Abbildung aus Bayraktar und Männer (2014).

Dies zeigt, dass es bei einem unter bilateral symmetrischen Bedingungen ablaufenden Bucklingprozess zu keiner Bevorzugung eines bestimmten Helix-Enantiomorphs kommt. Weitere Längenzunahmen des „,intra-perikardialen“ Anteils des Silikonstabs führten zu einer Abnahme der Steigung seiner helikalen Windung (Abb. 5D, E), bis der Silikonstab letztlich die Form einer zweihändigen Helix annahm (Abb. 5F). Hierbei nahmen linkshändige Helices regelmäßig die Form einer LR-händigen Helix an (Abb. 5D-F), während rechtshändige Helices regelmäßig die Form einer RL-händigen Helix annahmen (ohne Abbildung).

Fasst man die Ergebnisse dieses ersten Bucklingtests zusammen, so ist festzustellen, dass sich der Bucklingprozess in meinem physikalischen Modell in drei aufeinanderfolgende Phasen unterteilen lässt: (1.) sinusoidales Buckling (2.) simples helikales Buckling und (3.) komplexes helikales Buckling. Ausgehend von einer Länge von 136 mm (gerader Silikonstab) veränderte sich die Form des Silikonstabs unter stetiger Verlängerung des „intraperikardialen“ Anteils bei $183 \mathrm{~mm}$ Länge von einem sinusoidalen zu einem helikalen Buckling, während die Formänderung von einem simplen zu einem komplexen helikalen Buckling bei einer Länge von $327 \mathrm{~mm}$ erfolgte (Abb. 7). Am Ende des Bucklingtests betrug die Länge des „,intra-perikardialen“ Anteils des Silikonstabs das 2,57-Fache der craniocaudalen Länge der „Perikardhöhle“ (Abb. 7). 


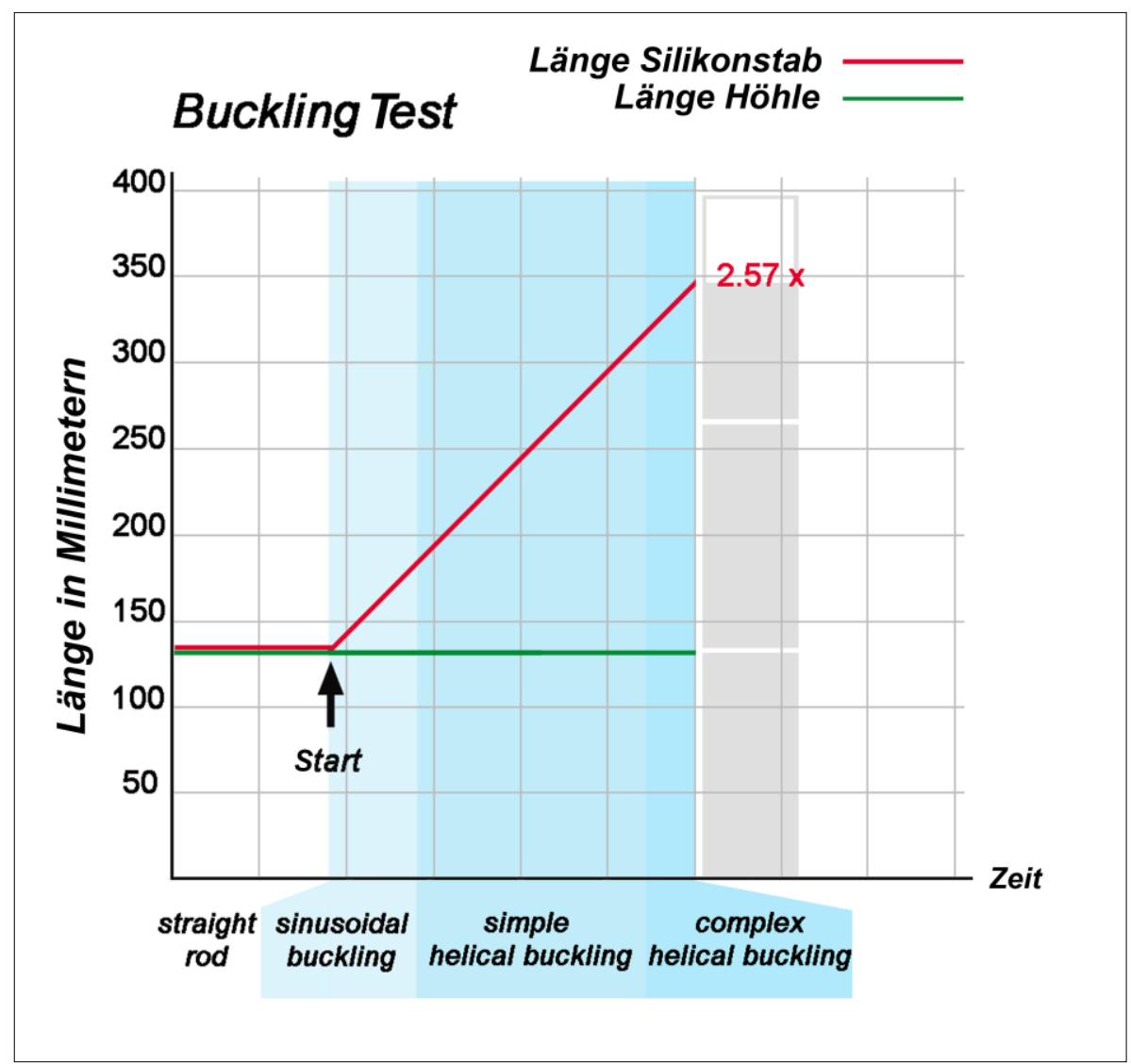

Abb. 7: Dieses Diagramm zeigt die Beziehung zwischen der Längenzunahme des „intraperikardialen" Anteils des Silikonstabs und dessen Formänderungen während des ersten Bucklingversuchs. Während des gesamten Experiments blieb die cranio-caudale Länge der „Perikardhöhle“ unverändert, wohingegen der „intra-perikardiale“ Anteil des Silikonstabs kontinuierlich an Länge zunahm. Zu Beginn des Bucklingtests war der „intra-perikardiale“ Anteil des Silikonstabs genauso lang wie die „Perikardhöhle“ (136 mm; Länge/Durchmesser-Verhältnis des Silikonstabs = 5,9). Die Längenzunahme des „intra-perikardialen“ Anteils des Silikonstabs führte zunächst zu sinusoidalem Buckling. Der Übergang von sinusoidalem zu simplem helikalem Buckling trat bei einer Länge von $183 \mathrm{~mm}$ ein (Länge/Durchmesser-Verhältnis des Silikonstabs = 7,96), während der Übergang von simplem helikalem Buckling zu komplexem helikalem Buckling bei einer Länge von $327 \mathrm{~mm}$ eintrat (Länge/Durchmesser-Verhältnis des Silikonstabs = 14,22). Am Ende des Versuchs betrug die Länge des „intra-perikardialen“ Anteils des Silikonstabs 350 mm (Länge/Durchmesser-Verhältnis des Silikonstabs = 15,22), womit dieser 2,57-mal so lang war wie die „Perikardhöhle“. Abbildung aus Bayraktar und Männer (2014)

\subsection{Experiment 2}

Um die Bedeutung der mechanischen Grenzen der Perikardhöhle für den im ersten Experiment beschriebenen Bucklingprozess zu prüfen, wurden die Tests in einem zweiten Experiment ohne die Halbkugel durchgeführt. Unter diesen Bedingungen führte eine stetige Längenzunahme des „intra-perikardialen“ Abschnitts des Silikonstabs lediglich zur Ausbildung und kontinuierlichen Zunahme einer Krümmung in der sagittalen Medianebene. Dieser Deformationsprozess lief solange, bis der gekrümmte Abschnitt des Silikonstabs unter seinem eigenen Gewicht instabil wurde und entweder nach rechts oder nach links umklappte (Abb. 8). Somit erfolgte beim Fehlen der ventro-lateralen Wände der „Perikardhöhle“ 
lediglich ein sinusoidales Buckling, d. h. es konnte kein simples oder komplexes helikales Buckling beobachtet werden.
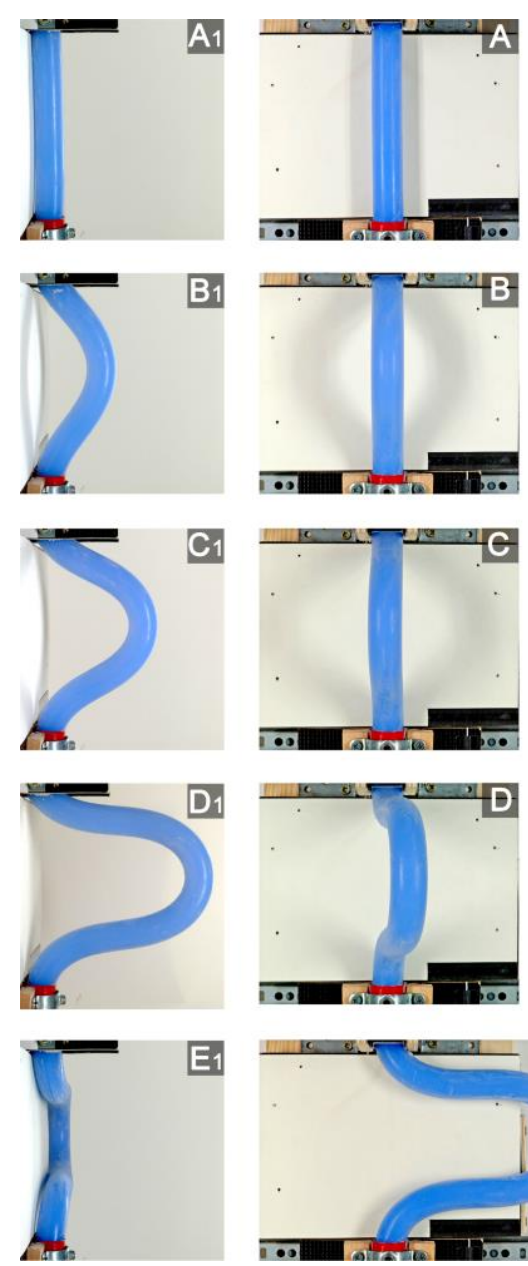

Abb. 8: Diese aus frontalen (A-E) und rechtslateralen (A1-E1) Ansichten aufgenommenen Fotos dokumentieren das Bucklingverhalten des „intra-perikardialen“ Anteils des Silikonstabs beim Fehlen der ventro-lateralen „Perikardhöhlenwände“. Unter dieser Bedingung ging das sinusoidale Buckling nicht in helikales Buckling über. Der sinusoidale Bucklingprozess setzte sich solange fort, bis die Struktur statisch instabil wurde und der Loop unter seinem eigenen Gewicht entweder nach links (E, E1) oder nach rechts klappte.

Abbildung aus Bayraktar und Männer (2014).

\subsection{Experiment 3}

Die phylogenetisch konservierte Determination der Händigkeit der Herzschleife wird häufig bereits vor dem Cardiac looping bestehenden Links-rechts-Asymmetrien zugeschrieben (Stalsberg 1970), z. B. einer geringfügigen Linksverlagerung des caudalen Endes des geraden Herzschlauchs (von Baer 1828; Schulte 1916; Biben und Harvey 1997). Dementsprechend wurden die Bucklingtests im dritten Experiment unter bilateral asymmetrischen Bedingungen durchgeführt, die durch links- oder rechtsseitige Verschiebung des caudalen Endes des Silikonstabs vor dem Bucklingtest hervorgerufen wurde. Unter diesen Bedingungen wurde der Bucklingprozess tatsächlich in Richtung der Erzeugung von nur einem von zwei möglichen Helix-Enantiomorphen gelenkt (Tabelle 1; Abb. 9). 


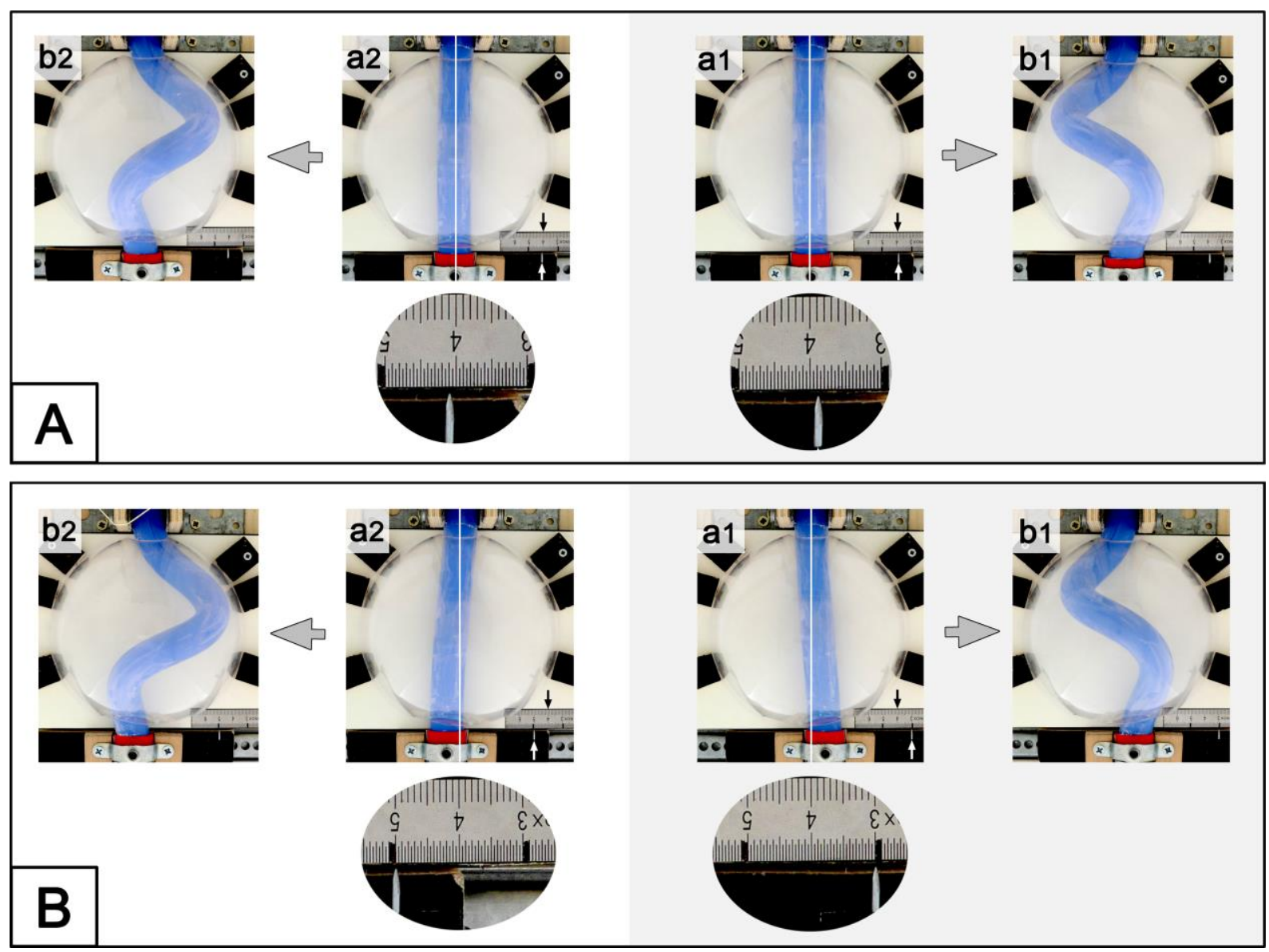

Abb. 9: Diese Fotos (Frontalansichten) zeigen Beispiele von Bucklingtests, die unter asymmetrischen Bedingungen abliefen (Experiment 3: Links- oder Rechtsverschiebung des caudalen Endes des Silikonstabs). A: $1 \mathrm{~mm}$ laterale Verschiebung vor Beginn des Bucklingversuchs. B: $10 \mathrm{~mm}$ laterale Verschiebung vor Beginn des Bucklingversuchs. Beachte, dass Linksverschiebungen (a1) linkshändige Helices erzeugten (b1), während Rechtsverschiebungen (a2) rechtshändige Helices (b2) erzeugten. Die „Körpermitte“ ist durch eine weiße Linie und die Linie 4 auf der Messskala (schwarzer Pfeil) gekennzeichnet. Die Position der Zentralachse des caudalen Endes ist durch einen Metallnagel angegeben, der auf die Messskala gerichtet ist (weißer Pfeil). Die runden und ovalen Ausschnitte zeigen Vergrößerungen der Messskala. Abbildung aus Bayraktar und Männer (2014).

Linksverschieben dirigierte den Bucklingprozess in Richtung der Erzeugung von linkshändigen Helices, während Rechtsverschieben den Bucklingprozess in Richtung der Erzeugung von rechtshändigen Helices lenkte. Bereits eine Verschiebung von nur $1 \mathrm{~mm}$ nach links oder rechts, was weniger als $5 \%$ des Durchmessers des Silikonstabs entspricht, reichte aus, um den Bucklingprozess in Richtung einer nahezu 100\%igen Erzeugung von links- bzw. rechtshändigen Helices zu lenken (Tabelle 1). 


\subsection{Experiment 4}

In den drei oben beschriebenen Experimenten war das caudale Ende des Silikonstabs während der gesamten Bucklingtests in der Mittellinie (Experimente 1 und 2), in linksseitigen oder in rechtsseitigen Positionen (Experiment 3) mechanisch fixiert. Während des Dextral-Loopings des embryonalen Wirbeltierherzens bleibt das caudale Ende des Herzschlauchs (der zukünftige Atrioventrikularkanal) jedoch nicht in seiner anfänglichen Position, sondern verlagert sich kontinuierlich nach links (Murray 1919; De Vries und Saunders 1962; Biben und Harvey 1997). Wir wollten herausfinden, ob diese Verlagerung möglicherweise eine Folge eines Bucklingprozesses sein könnte. Dementsprechend wurde ein abschließendes Experiment ohne mechanische Fixierung des caudalen Schlittens durchgeführt, sodass sich das caudale Ende des Silikonstabs während des Bucklingtests auf der Links-rechts-Achse frei bewegen konnte. Es zeigte sich, dass unter diesen Bedingungen die Entstehung einer linkshändigen Helix mit einer Linksverlagerung des caudalen Endes (Abb. 10) einherging, während die Entstehung einer rechtshändigen Helix mit einer Rechtsverlagerung des caudalen Endes einherging (ohne Abbildung).
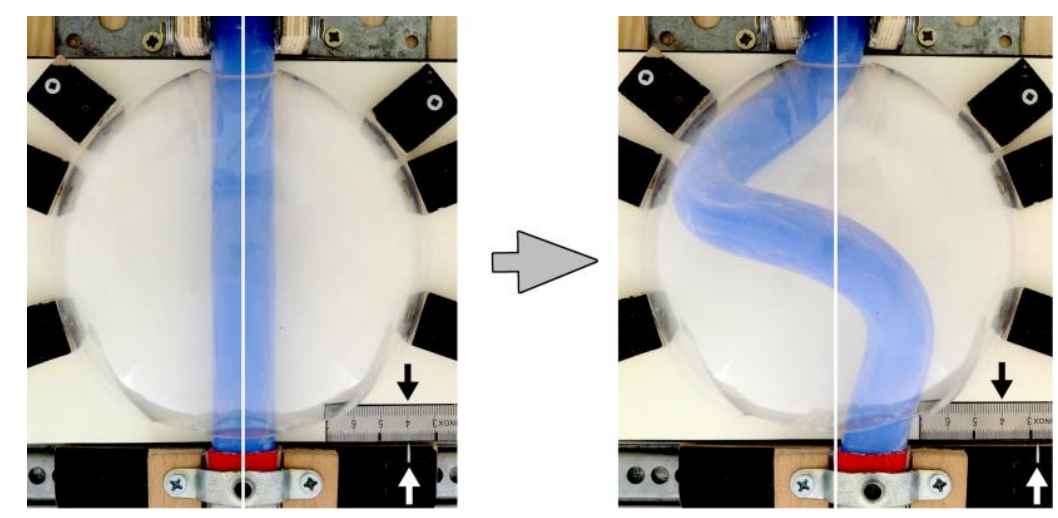

Abb.10: Diese Fotos (Frontalansicht) zeigen die Linksverschiebung des caudalen Endes des Silikonstabs, welche durch den linkshändigen helikalen Bucklingprozess hervorgerufen wurde. A: Der gerade Silikonstab vor Beginn des Bucklingtests. Beachte die Mittellinienposition der Zentralachse des Silikonstabs. B: Der Silikonstab während des helikalen Bucklings. Beachte die Linksverschiebung des caudalen Endes des Silikonstabs. Abbildung aus Bayraktar und Männer (2014). 


\section{Diskussion}

Während der letzten 200 Jahre fokussierte sich die Forschung zum Phänomen des Cardiac looping auf die Beantwortung von zwei Hauptfragen: (1.) Welche Faktoren sind für die normalen Lage- und Formänderungen des embryonalen Herzschlauchs verantwortlich und (2.) welche Faktoren determinieren die phylogenetisch hochkonservierte Händigkeit der schraubig gewundenen Herzschleife? Die von mir durchgeführten Bucklingtests könnten einen Beitrag zur Beantwortung beider Fragen leisten, indem sie zur Identifizierung von mechanischen Determinanten des Loopingprozesses beisteuern.

Bezüglich der ersten Frage zeigte sich, dass durch wachstumbedingtes Buckling eines geraden elastischen Silikonstabs innerhalb einer räumlich begrenzenden halbkugeligen Höhle eine Abfolge von Formänderungen erzeugt werden kann, die der Abfolge von Formänderungen der Looping-Morphogenese von Herzschläuchen höherer Wirbeltierembryonen entspricht (Abb. 5). Beide Prozesse beginnen mit der Biegung eines initial geraden Stabs/Schlauchs entlang einer Ebene (sinusoidales Buckling; Abb. 5B). Nachdem die Konvexität des sich krümmenden Stabs/Schlauchs in Kontakt mit der Wand der ihn begrenzenden Höhle kommt, wandelt sich der zweidimensionale in einen dreidimensionalen Krümmungsprozess um, wobei der Stab/Schlauch zunächst die Form einer einhändigen Helix (simples helikales Buckling; Abb. 5C-E) und abschließend die Form einer zweihändigen Helix annimmt (komplexes helikales Buckling; Abb. 5F).

In unserem Bucklingexperiment betrug die Länge der zweihändigen Helix (das „S-förmige“ Herz) das 2,57-Fache der cranio-caudalen Länge der „Perikardhöhle“ (Abb. 7). Dieser Wert passt gut zum entsprechenden Wert bei Axolotlembryonen (x 2,64; Abb. 2A), ist allerdings geringer als der Wert bei Hühnerembryonen (x 3,37; Abb. 2B) und etwas größer als der Wert, der für menschliche Embryonen angegeben wurde (x 2,0; Davis 1927). Diese Unterschiede könnten in den unterschiedlichen Formen und/oder relativen Größen der Herzschläuche und Perikardhöhlen begründet sein (z. B. Verhältnis Länge zu Durchmesser des Herzschlauchs). Des Weiteren zeigte sich, dass das Auftreten von einfachen oder komplexen helikalen Deformationen abhängig von mechanischen Grenzen ist, die den Wänden der halbkugeligen Höhle entsprechen (Abb. 8). Sämtliche Beobachtungen stehen im Einklang mit der Hypothese des wachstumsbedingten Bucklings, die besagt, dass die Form- und Lageänderungen der embryonalen Herzschleife hauptsächlich auf Kompressionsbelastungen zurückzuführen sind, die aus dem ungleichen Längenwachstum von Herzschlauch und Perikardhöhle resultieren. 
Bezüglich der zweiten Frage haben meine Experimente gezeigt, dass bei einem unter bilateral symmetrischen Bedingungen ablaufenden helikalen Bucklingprozess links- und rechtshändige Helices in einem Zahlenverhältnis von 1:1 auftreten, während bereits geringfügige Linksoder Rechtsverschiebungen des unteren Endes des Silikonstabs vor dem Bucklingtest ausreichen, um den Bucklingprozess in Richtung einer Erzeugung von ausschließlich linksoder rechtshändigen Helices zu lenken (Tabelle 1, Abb. 6, 9). Diese Beobachtungen stehen im Einklang mit der Hypothese, dass bereits eine geringfügige Linksverschiebung des caudalen Endes des Herzschlauchs vor Beginn des Cardiac looping einen entscheidenden Beitrag zur Determinierung des D-Loop-Enantiomorphs leisten könnte (von Baer 1828; Schulte 1916; Biben und Harvey 1997).

Zusammenfassend lässt sich demnach feststellen: (1.) Mittels eines physikalischen Simulationsmodells konnte ich zum ersten Mal die physikalische Plausibilität der Hypothese des wachstumsbedingten Bucklings bestätigen. (2.) Mittels desselben Modells konnte ich weiterhin zeigen, dass asymmetrische Positionierungen des venösen Herzpols im Rahmen von Bucklingprozessen eine händigkeitsdeterminierende Rolle spielen. Hierdurch konnte ich die physikalische Plausibilität entsprechender Hypothesen zur Determination der Händigkeit der Herzschleife bestätigen.

Nachdem ich nun in einem ersten Schritt die physikalische Plausibilität der Hypothese des wachstumsbedingten Bucklings mittels eines Modells bestätigen konnte, soll diese Hypothese in den folgenden Abschnitten der Diskussion anhand der in der Literatur beschriebenen Daten auf ihre biologische Plausibilität hin geprüft werden.

\subsection{Zur Bedeutung ungleichen Wachstums für die Formbildung der embryonalen Herzschleife}

Nach der Hypothese des wachstumsbedingten Bucklings handelt es sich beim Cardiac looping um einen Deformationsprozess, der hauptsächlich durch zwei mechanische Kräfte hervorgerufen wird: (1.) eine kontinuierlich zunehmende axiale Kompressionslast, die aus dem ungleichen Längenwachstum des embryonalen Herzschlauchs und der ihn beherbergenden Perikardhöhle resultiert (Abb. 2) und (2.) eine Kompressionsbelastung des Herzschlauchs, die aus der räumlichen Begrenzung seiner kontinuierlich fortschreitenden sinusoidalen Verbiegung durch die ventro-lateralen Wände der Perikardhöhle resultiert. Die 
Größen beider Kräfte sollten vom Wachstumsverhalten des Herzschlauchs und der Perikardhöhle abhängig sein. Würde beispielsweise das Ausmaß der Längenzunahme des embryonalen Herzschlauchs auf das normale Ausmaß der cranio-caudalen Längenzunahme der Perikardhöhle reduziert, wäre zu erwarten, dass die axiale Kompressionslast des Herzschlauchs gegen null geht, und die zu erwartende Form des Herzens wäre die eines geraden Schlauchs. Der qualitativ gleiche Phänotyp wäre zu erwarten, wenn das Ausmaß der cranio-caudalen Längenzunahme der Perikardhöhle auf das Ausmaß der normalen Längenzunahme des embryonalen Herzschlauchs erhöht würde. Bei exzessivem Längenwachstum des Herzens innerhalb einer normal großen Perikardhöhle oder bei normalem Längenwachstum des Herzens innerhalb einer zu kleinen Perikardhöhle müssten hingegen abnorm hohe Werte der axialen Kompressionslast erzeugt werden, die zu einer übermäßig stark gewundenen Herzschleife führen müssten.

Nahezu sämtliche der oben genannten hypothetischen Situationen wurden bereits bei Tiermodellen mit Anomalien des Cardiac looping dokumentiert. Fotos von Embryonen, von denen berichtet wird, dass sie nicht (gerader Herzschlauch) oder unvollständig gebogene Herzschleifen entwickeln, zeigen entweder abnorm kurze Herzschläuche innerhalb einer normal großen Perikardhöhle (z. B. Abb. 1 in Yelbuz et al. 2002; Abb. 5 in Brade et al. 2007; Abb. 2 in Klaus et al. 2007; Abb. 1 in Niu et al. 2008; Abb. 5 in Choudhry und Trede 2013) oder nahezu normal große Herzschläuche innerhalb einer abnorm vergrößerten Perikardhöhle (z. B. Abb. 5 in Breckenridge et al 2001; Abb. 1 in Garrity et al. 2002; Abb. 3 in Ribeiro et al. 2007; Abb. 2 in Doherty et al. 2010). Andererseits zeigen Fotos von Embryonen, von denen berichtet wird, dass sie übermäßig stark gewundene Herzschleifen entwickeln, einen abnorm langen Herzschlauch innerhalb einer annähernd normal großen Perikardhöhle (Abb. 3 in Risebro et al. 2006).

Diese Beobachtungen lassen vermuten, dass eine signifikante Anzahl von Störungen des Cardiac looping, die bei Tiermodellen gefunden wurden, insbesondere von LoopingAnomalien in Tiermodellen mit gestörter Entwicklung der Herzfelder, primär nicht auf Störungen von spezifischen formgenerierenden oder -regulierenden Prozessen beruhen, sondern eher von verändertem Wachstumsverhalten des Herzschlauchs und der ihn beherbergenden Perikardhöhle herrühren. Demnach scheint es so $\mathrm{zu}$ sein, dass Wachstumsdifferenzen zwischen dem Herzschlauch und der ihn beherbergenden Perikardhöhle nicht nur in meinem Simulationsmodell wichtige Determinanten in der Gestaltbildung der Herzschleife darstellen, sondern auch in der biologischen Wirklichkeit. 
Die genannten biologischen Befunde stehen somit im Einklang mit der Hypothese des wachstumsbedingten Bucklings.

\subsection{Zur Mechanik der ventralen Biegung der Herzschleife}

Die erste auffällige Formänderung des embryonalen Herzschlauchs beim Loopingprozess ist die ventrale Biegung des späteren Kammeranteils der Herzschleife. Die Hypothese des wachstumsbedingten Bucklings interpretiert diese Biegung als das Ergebnis eines Deformationsprozesses (sinusoidales Buckling), der aus einer axialen Kompression des Herzschlauchs resultiert. In meinem Simulationsmodell konnte die physikalische Plausibilität dieses Konzepts bestätigt werden. Wenn wir nun die Buckling-Hypothese auf ihre biologische Plausibilität hin prüfen, fällt auf, dass Versuche an biologischen Modellen - wie beispielsweise In-vitro-Kulturen von isolierten embryonalen Herzschläuchen - die biologische Plausibilität des Buckling-Konzepts scheinbar widerlegen.

Sollte die ventrale Biegung des embryonalen Herzschlauchs ausschließlich durch sinusoidales Buckling verursacht sein, wäre $\mathrm{zu}$ erwarten, dass ein gerader Herzschlauch sich nicht verbiegt, wenn er aus der Perikardhöhle entfernt wird und in einem In-vitro-System als isoliertes Präparat kultiviert wird. Im Gegensatz zu dieser Erwartung hat sich jedoch gezeigt, dass isolierte embryonale Herzschläuche eine intrinsische Kapazität für die ventrale Biegung aufweisen (Ekman 1925; Bacon 1945; Butler 1952; Manning und McLachlan 1990; Flynn et al. 1991). Darüber hinaus legen einige experimentelle Daten nahe, dass die intrinsische Biegung der embryonalen Herzschleife durch myokardiale Zellformänderungen angetrieben wird, die auf Aktinpolymerisierung beruhen könnten (Latacha et al. 2005; Rémond et al. 2006; Taber 2006). Angesichts dieser Daten scheint es unwahrscheinlich, dass die ventrale Biegung des embryonalen Herzschlauchs hauptsächlich aus wachstumsbedingter axialer Kompression resultiert.

Aufgrund der im vorhergehenden Abschnitt diskutierten biologischen Daten scheint es jedoch ebenfalls wenig wahrscheinlich $\mathrm{zu}$ sein, dass die ventrale Biegung des embryonalen Herzschlauchs im intakten Embryo ausschließlich auf intrinsischen Biegungsmechanismen beruht. Wir vermuten daher, dass aktive Zellformänderungen in der biologischen Wirklichkeit eine führende Rolle bei der ventralen Biegung des Herzschlauchs spielen könnten, wohingegen das Wachstumsverhalten des embryonalen Herzens und der Perikardhöhle in 
diesem Prozess weniger eine aktive als vielmehr eine gewährende Rolle innehat. Anzumerken ist noch, dass nicht alle bisher veröffentlichten biologischen Daten die Hypothese eines durch Zellformänderungen angetriebenen intrinsischen Biegemechanismus stützen. So konnten Hill und Lemanski (1979) in In-vitro-Kulturen von explantierten embryonalen Amphibienherzen kein Fortschreiten des Loopingprozesses beobachten. Weiterhin legen Ergebnisse von colchicinbehandelten Hühnerembryonen nahe, dass die während des Biegungsprozesses zu beobachtenden Zellformänderungen lediglich das Ergebnis und nicht die Ursache dieses Formbildungsprozesses darstellen (Icardo und Ojeda 1984).

\subsection{Zur Mechanik der schraubigen Verformungen der Herzschleife}

Beim In-vitro-Looping isolierter embryonaler Herzschläuche soll es sich um einen Biegungsprozess handeln, der lediglich in einer Ebene abläuft (planares Looping) und somit keine schraubig gewundenen Herzschleifen erzeugt (Flynn et al. 1991; Latacha et al. 2005; Rémond et al. 2006; Taber et al. 2013). Aus diesem Grund wird die Umformung des gekrümmten Herzschlauchs in eine schraubig gewundene Herzschleife hauptsächlich Faktoren zugeschrieben, die außerhalb des sich entwickelnden Herzens liegen (Taber 2006; Taber et al. 2010).

Es mag verlockend sein, anzunehmen, dass diese extrinsischen Faktoren auf eine bilateral asymmetrische Art wirken, um aus dem primär symmetrischen Herzschlauch eine asymmetrische Herzschleife $\mathrm{zu}$ erzeugen. Meine Experimente haben jedoch gezeigt, dass helikale Formen auch in einem Bucklingprozess entstehen können, der unter bilateral symmetrischen Bedingungen abläuft, wobei die initiale Symmetrie des Systems ihren Ausdruck in einem statistisch randomisierten Auftreten der beiden möglichen Enantiomorphe findet. Daher vermute ich, dass die Erzeugung einer helikalen Herzschleife bei Wirbeltierembryonen nicht zwangsläufig - wie vielfach vermutet wurde (Stalsberg 1971) vom Vorhandensein struktureller oder funktioneller Asymmetrien abhängig ist. Ich gehe davon aus, dass diese Asymmetrien eher bei der Determination der Händigkeit der Herzschleife eine bedeutende Rolle spielen. Diese Vermutung wird durch experimentelle Daten von Hühner- und Zebrafischembryonen gestützt. Diese Daten zeigen, dass die künstliche Erzeugung von molekularer und morphologischer Symmetrie den Loopingprozess des Herzschlauchs nicht verhindert, sondern lediglich zu einem randomisierten Auftreten von D- und L-Loops führt (Breckenridge et al. 2001; Kidokoro et al. 2008). Aus diesem Grund 
werde ich die Mechanik des helikalen Loopings und das Problem der Determination der Händigkeit der Herzschleife in zwei verschiedenen Abschnitten diskutieren.

Das vorliegende Simulationsmodell hat gezeigt, dass die Erzeugung von einfachen und komplexen helikalen Formen in einem Bucklingprozess von mechanischen Grenzen abhängig ist, die das Ausmaß eines kontinuierlich fortschreitenden sinusoidalen Biegungsprozesses räumlich begrenzen. Sollte die schraubige Gestalt der embryonalen Herzschleife von einem Bucklingprozess herrühren, wäre demnach zu erwarten, dass ein sich biegender Herzschlauch nicht in der Lage wäre, eine helikale Form einzunehmen, wenn er (1.) aus der Perikardhöhle entfernt und in vitro ohne räumliche Begrenzungen kultiviert wird oder (2.) sich in einer Perikardhöhle entwickelt, deren ventro-laterale Wände vor oder während der initialen Phase des Cardiac looping entfernt wurden.

Experimentelle Daten von Hühnerembryonen haben gezeigt, dass (1.) beim In-vitro-Looping isolierter Herzschläuche keine helikal gewundenen Herzschleifen entstehen (siehe oben) und dass (2.) das Entfernen der ventralen Wand der primären Perikardhöhle zu Beginn des Cardiac looping die Torsion unterbindet, die normalerweise zur Umformung des gebogenen Herzschlauchs in eine helikal gewundene Herzschleife führt (Voronov und Taber 2002; Voronov et al. 2004). Beide Beobachtungen stimmen mit den oben genannten Erwartungen überein und könnten somit als Beleg für die Gültigkeit der Hypothese des wachstumsbedingten Bucklings angesehen werden. Allerdings ist anzumerken, dass andere experimentelle Daten gezeigt haben, dass (1.) die torsionsverhindernden Effekte der Entfernung der ventralen Perikardwand nur von temporärer Natur sind und dass es (2.) beim Fehlen der durch die ventrale Perikardwand erzeugten Kompressionslast zu einem zeitlich verzögerten Auftreten der Torsion kommt, wobei diese Torsion durch einen normalerweise nicht am Dextral-Looping beteiligten Mechanismus verursacht wird, namentlich durch zytoskeletale Kontraktion des Myokards (Nerurkar et al. 2006).

Demnach lässt sich anhand der gegenwärtig zur Verfügung stehenden experimentellen Daten kein klares Bild über die Biomechanik der einfachen und komplexen helikalen Verformungen der embryonalen Herzschleife gewinnen. Auf der einen Seite gibt es Daten, die nahelegen, dass diese Formänderungen normalerweise durch Kompressionslasten erzwungen werden, die aus einem ungleichen Wachstum des Herzens und der es beherbergenden Perikardhöhle resultieren (Voronov und Taber 2002; Voronov et al. 2004). Auf der anderen Seite existieren Daten, die nahelegen, dass der embryonale Herzschlauch eine latente intrinsische Tendenz zur 
Ausbildung einer helikalen Windung besitzen könnte. Bei dieser intrinsischen Tendenz könnte es sich um einen regulatorischen Mechanismus handeln, der im Fall des Fehlens der ventralen Perikardwand aktiv wird und somit sicherstellt, dass die Formbildung der embryonalen Herzschleife auch unter veränderten Bedingungen normal ablaufen kann (Nerurkar et al. 2006).

\subsection{Zur Mechanik der Determination der Händigkeit der Herzschleife}

Die Frage, wie die Händigkeit der embryonalen Herzschleife determiniert wird, beschäftigt Biologen seit dem 19. Jahrhundert. Entsprechend wurden in den letzten 200 Jahren diverse biophysikalische Mechanismen vorgeschlagen, die den Loopingprozess regelhaft in Richtung Dextral-Looping lenken sollen. Die meisten dieser biomechanischen Vorstellungen wurden durch experimentelle Daten widerlegt (Taber 2006), sodass aktuell nur noch zwei relativ gut fundierte Konzepte diskutiert werden. Das erste Konzept schreibt die Determination der Händigkeit einer bilateral asymmetrischen Verteilung von Schub- und Zugkräften entlang des venösen Herzpols zu. Die stärkere linke Vene soll die sich biegende Kammerschleife nach rechts kippen (Taber 2006; Taber et al. 2010). Das zweite Konzept begründet die Determination der Händigkeit mit bilateral asymmetrischen Zellproliferationsmustern innerhalb des dorsalen Mesokards und des Vorderdarm-Endoderms (Linask et al. 2005; Linask und Vanauker 2007).

Mit dem vorliegenden Simulationsmodell habe ich zum ersten Mal die physikalische Plausibilität eines dritten Konzepts geprüft, welches die Determination des D-LoopEnantiomorphs einer geringfügigen Linksverschiebung des venösen Herzpols kurz vor Beginn des Loopings zuschreibt. Bereits im 19. Jahrhundert erkannte der Embryologe Karl Ernst von Baer $(* 1792, \uparrow 1876)$, dass diese Asymmetrie möglicherweise eine entscheidende Rolle bei der Determinierung der Händigkeit der Herzschleife spielen könnte. Er vermutete, dass die Linksverschiebung des venösen Herzendes $\mathrm{zu}$ einem von links nach rechts gerichteten Verlauf des intrakardialen Blutflusses führt, der seinerseits eine nach rechts gerichtete Kippung der sich entwickelnden Kammerschleife verursacht (von Baer 1828). Obgleich mehrere Forscher bemerkten, dass ein solcher hämodynamischer Mechanismus im Widerspruch zu der Tatsache steht, dass das Cardiac looping lange vor dem Beginn des Blutflusses einsetzt, findet sich von Baers Hypothese in vielen embryologischen Arbeiten des 19. Jahrhunderts. Während des 20. Jahrhunderts wurde die Linksverschiebung des venösen 
Herzendes in einigen Veröffentlichungen beschrieben (Murray 1919; De Vries und Saunders 1962), doch schien die Idee einer händigkeitsdeterminierenden Rolle dieser Asymmetrie vergessen. Erst Mitte der 1990er Jahre erlebte diese Idee durch die Arbeit von Biben und Harvey (1997) eine Art Wiedergeburt. Die letztgenannten Autoren vermuteten zwar, dass die frühe Linksverschiebung des venösen Herzpols ein entscheidendes Ereignis bei der Determinierung des Herzsitus sein könnte, doch konnten sie keine mechanistische Erklärung liefern. Das vorliegende Simulationsmodell zeigt zum ersten Mal, dass die Idee einer händigkeitsdeterminierenden Rolle einer asymmetrischen Positionierung des venösen Herzpols im Rahmen von Bucklingprozessen physikalisch plausibel ist. Es bleibt zukünftigen Studien vorbehalten, diese Idee auf ihre biologische Plausibilität hin zu prüfen. Hierbei wäre es u. a. von Interesse, zu prüfen, ob die frühe Linksverschiebung des venösen Herzpols embryonaler Säugetierherzen homolog zum Phänomen des Leftward jogging des Herzschlauchs von Zebrafischembryonen ist (Chen et al. 1997; Chin et al. 2000; Khodiyar et al. 2014).

Basierend auf den Daten meines Simulationsmodells lassen sich Voraussagen machen, die in zukünftigen Studien an Tiermodellen überprüft werden könnten. Bei Mausmodellen mit einem statistisch ausgeglichenen Auftreten von D- und L-Loops (1:1) würde man beispielweise erwarten, vor Beginn des Loopingprozesses einen von drei alternativen Phänotypen zu finden: (1.) ein 1:1-Verhältnis von Links- und Rechtsverschiebung des venösen Herzpols (2.) das Fehlen von seitlichen Verschiebungen des venösen Herzpols (Mittellinienposition) (3.) ein 1:2:1-Verhältnis von Linksverschiebung, Mittellinienposition und Rechtsverschiebung des venösen Herzpols. Bei Mausmodellen mit vorherrschendem Auftreten von L-Loops wiederum wäre eine entsprechende Tendenz zur Rechtsverschiebung des venösen Herzpols vor dem Loopingprozess zu erwarten. Beispiele solcher seltenen Tiermodelle sind (1.) Mäuse mit Homozygotie für eine Mutation im Inversin-Gen, bei denen sich eine nahezu 100\%ige Inzidenz von L-Loops findet (Yokoyama et al. 1993) und (2.) Mäuse mit einem funktionslosen Allel des Dnaic1-Gens, die eine 60\%ige Inzidenz von L-Loops zeigen (Francis et al. 2012).

Eine händigkeitsdeterminierende Rolle von bilateral asymmetrischen Positionierungen des venösen Herzpols könnte ebenfalls ein rätselhaftes Phänomen erklären, das bei einer Entwicklungsanomalie namens Cardia bifida beobachtet wird. Diese Anomalie ist durch die Entwicklung zweier voneinander getrennter Herzen gekennzeichnet, von denen eines auf der linken und das andere auf der rechten Körperseite liegt. Eine Cardia bifida ist ein bei Tieren 
und Menschen außerordentlich seltener nachgeburtlicher Befund (Panum 1859; Aiello et al. 1987; Aiello und Xavier-Neto 2006). Sie ist Embryologen jedoch gut bekannt, da sie durch mikrochirurgische Eingriffe oder genetische Defekte künstlich erzeugt werden kann, durch welche die Vereinigung der linken und rechten Herzfelder ausbleibt (Gräper 1907; Copenhaver 1926; DeHaan 1959; Zwirner und Kuhlo 1964; Nadal-Ginard und Paz Garcia 1972; Li et al. 2004).

Bei Embryonen mit Cardia bifida wurde berichtet, dass die linke Herzschleife nahezu immer das D-Loop-Enantiomorph annimmt, während die rechte Herzschleife das L-LoopEnantiomorph ausbildet (Ekman 1925; Copenhaver 1926; Zwirner und Kuhlo 1964; NadalGinard und Paz Garcia 1972). Dieses Phänomen führte zu der Hypothese, dass jedes Herzfeld seine eigene enantiomorphe Tendenz besitzen könnte (Weiss 1930; Zwirner und Kuhlo 1964), die allerdings nur bei ausbleibender Vereinigung der Herzfelder zur Ausprägung käme. Bei einer Vereinigung der Herzfelder jedoch würde die enantiomorphe Tendenz des rechten Herzens nicht zur Ausprägung kommen, da sie von der des linken Herzens dominiert würde (Weiss 1930; Zwirner und Kuhlo 1964). Die Hypothese einer morphogenetischen Dominanz der linken Herzanlage scheint von der Beobachtung gestützt zu werden, dass im Fall einer Cardia bifida das linke Herz generell größer ist und früher, schneller und stärker pulsiert als das rechte (Bacon 1945; DeHaan 1958, 1959, Zwirner und Kuhlo 1964; Lepori 1967). Entsprechende Beobachtungen wurden in Kulturen von isolierten Herzfeldern gemacht (Goerttler 1928; Rawles und Williers 1934).

So verlockend die Hypothese einer linksseitigen morphogenetischen Dominanz auch erscheinen mag, muss festgestellt werden, dass sie bereits in der ersten Hälfte des 20. Jahrhunderts durch mehrere Experimente widerlegt wurde (Ekman 1925; Stöhr 1925, 1926; Fales 1946). Aktuell gibt es daher keine plausible Erklärung für das üblicherweise bei Cardia bifida auftretende Muster der kardialen Händigkeiten. Wenn man Abbildungen des Herzsitus von Amphibienembryonen mit Cardia bifida betrachtet, fällt auf, dass die arteriellen Pole der beiden Herzschleifen nahe der Körpermitte liegen, während deren venöse Pole einen größeren Abstand zur Mittellinie zeigen (z. B. Abb. 26 in Copenhaver 1926). Demnach liegt bei den rechten Herzen, die üblicherweise die Form eines L-Loops annehmen, der venöse Pol rechts vom arteriellen Pol, während bei den linken Herzen, die üblicherweise die Form eines DLoops annehmen, der venöse Pol links vom arteriellen Pol liegt. Die Ergebnisse meiner Bucklingexperimente verleiten zu der Annahme, dass die Lagebeziehungen zwischen den arteriellen und den venösen Enden der Herzschläuche verantwortlich sind für die Entwicklung 
des bei Cardia bifida üblichen räumlichen Verteilungsmusters von D- und L-LoopEnantiomorphen.

\subsection{Zur mechanischen Stabilität der bei Bucklingprozessen erzeugten Deformationen}

Die in meinem Modell erzeugten Deformationen eines ursprünglich geraden, elastischen Stabs sind nicht stabil. Sobald die Kompressionslast entfernt wird, strebt der Stab aufgrund seiner Eigenelastizität danach, in seine ursprüngliche Form zurückzukehren. Ein derartiges Formverhalten wird allgemein als elastische Deformation bezeichnet, während man unumkehrbare Deformationen als plastische Deformationen bezeichnet. Ein der elastischen Deformation entsprechendes Verhalten zeigt der Herzschlauch von Hühnerembryonen, wenn die ventrale Wand der Perikardhöhle während der initialen Phase des Dextral-Loopings entfernt wird (HH-Stadium 11). In diesem Fall verliert die Herzschleife ihre bereits angenommene helikale Form und behält lediglich ihre sinusoidale Krümmung bei (Voronov und Taber 2002; Voronov et al. 2004). Entfernt man jedoch die ventrale Perikardwand in einem fortgeschrittenen Stadium des Cardiac looping (z. B. HH-Stadium 18), behalten embryonale Herzschleifen ihre komplexe helikale Form (eigene, nicht publizierte Beobachtungen).

Sollten die schraubigen Deformationen der Herzschleife hauptsächlich von wachstumsbedingten Kompressionslasten verursacht werden, lässt sich der letztgenannte Befund nur durch einen Wechsel von elastischer zu plastischer Deformation erklären. Ein solcher Wechsel könnte entweder durch einen Elastizitätsverlust der Herzwand oder durch die Existenz von aktiven formstabilisierenden Mechanismen innerhalb des sich entwickelnden Herzens verursacht sein. Die Existenz von formstabilisierenden Mechanismen wurde von dem russischen Entwicklungsbiologen Beloussov postuliert und durch Experimente an Geweben von Amphibienembryonen nachgewiesen (Beloussov und Grabovsky 2006; Kremnyov et al. 2012). Die in fortgeschrittenen Stadien des Cardiac looping zu beobachtende Formstabilität der embryonalen Herzschleife steht somit nicht im Widerspruch zur Hypothese des wachstumsbedingten Bucklings. 


\section{Limitationen meines Simulationsmodells}

Jedes Simulationsmodell hat seine Limitationen, da es nur eine klar definierte Anzahl von Faktoren berücksichtigt, von denen der Untersuchende erwartet, dass sie eine entscheidende Rolle bei dem zu simulierenden Prozess spielen. Dementsprechend ist zu bedenken, dass das durch mein Modell vermittelte Bild der Herzschleifenbildung zu einer Überbewertung der in diesem Modell untersuchten mechanischen Faktoren führen kann. Frühere experimentelle Daten legen nahe, dass die Formänderungen der embryonalen Herzschleife normalerweise durch mehrere voneinander unabhängige mechanische Faktoren erzeugt werden. Diese Faktoren verursachen z. T. überlappende Effekte und könnten somit kooperativ wirken (Stalsberg 1970; Manasek 1981). Die Daten meines Modells schließen die Möglichkeit nicht aus, dass weitere mechanische Faktoren wichtige Beiträge zum Cardiac looping leisten.

Auf der Liste derartiger in meinem Simulationsmodell nicht berücksichtigter Faktoren stehen: (1.) aktive Änderungen der myokardialen Zellform, die für die intrinsische Biegung des Herzschlauchs verantwortlich gemacht werden (siehe oben); (2.) lokale Unterschiede in der mechanischen Beschaffenheit (Steifigkeit) des Herzschlauchs, welche den durch aktive Zellformänderungen bedingten Krümmungsprozess erleichtern könnten (Zamir et al. 2003); (3.) lokale Unterschiede im Wachstumsverhalten des Kammermyokards, die über eine Expansion der äußeren Kurvatur der Kammerschleife (Ballooning) zum Cardiac looping beitragen könnten (De Boer et al. 2012); (4.) Kompressionen der Herzschleife, die durch die Bildung der normalen Körperkrümmungen des Embryos (Zervikalflexion) hervorgerufen werden und eine wichtige Rolle beim S-Looping spielen (Männer et al. 1993, 1995; Männer 2004; Ramasubramanian et al. 2013); (5.) bilateral asymmetrische Verteilungen von Schubund Zugkräften entlang des venösen Herzpols, die entscheidende Rollen bei der rechtsgerichteten Torsion des embryonalen Hühnerherzens spielen sollen (Ramasubramanian et al. 2006; Taber 2006; Taber et al. 2010); und (6.) bilateral asymmetrische Muster der Zellproliferation ( $\mathrm{L}>\mathrm{R}$ ) im dorsalen Mesokard und im Vorderdarm-Endoderm, die ebenfalls bei der rechtsgerichteten Torsion mitwirken könnten (Linask et al. 2005; Linask und Vanauker 2007).

Eine weitere Limitation meines Modells ist die Tatsache, dass es ein primär qualitatives Modell ist, welches aus idealisierten geometrischen Elementen besteht und keine realen Materialeigenschaften aufweist (siehe Materialien und Methodik). Demnach ist das in meinem Modell beobachtete Formverhalten des Herzschlauchs als ein geometrisch 
idealisiertes Verhalten anzusehen, welches nicht exakt mit dem Formverhalten echter embryonaler Herzen übereinstimmen muss. Es ist eine Herausforderung zukünftiger Studien, Simulationsmodelle zu entwickeln, mit denen es möglich ist, die physikalische Plausibilität der Hypothese des wachstumsbedingten Bucklings unter Bedingungen zu testen, die näher an der biologischen Realität liegen.

Abschließend sei angemerkt, dass mein Simulationsmodell lediglich die physikalische Plausibilität der Hypothese des wachstumsbedingten Bucklings bestätigt hat. Es kann keinen Beweis für die Gültigkeit dieser Hypothese in echten biologischen Systemen liefern. Biologische Objekte mit der gleichen geometrischen Form können durch verschiedene formbildende Mechanismen erzeugt werden. Aufgrund dieses Phänomens, das auch als Phänokopie bezeichnet wird, kann man nicht sicher sein, dass die in meinem Modell wirkenden Kräfte auch beim realen Cardiac looping in gleicher Weise wirken.

Um das Problem der Phänokopie näher zu erläutern, sei angemerkt, dass kürzlich gezeigt wurde, dass der Prozess der Umwandlung von initial gestreckten Ranken von Kletterpflanzen in spiralfederartig gewundene Gebilde durch die gleichen globalen Formänderungen (sinusoidale Biegung, einfache helikale Windungen, komplexe helikale Windungen) gekennzeichnet ist wie der Prozess des Cardiac looping (Männer 2013). Diese Beobachtung führte zu der Hypothese, dass das Cardiac looping und die Windungsprozesse von Ranken von den gleichen physikalischen Formbildungsmechanismen verursacht werden könnten (Männer 2013). Im Gegensatz zu meinem Simulationsmodell sind die schraubigen Windungen von Ranken nicht das Ergebnis eines Bucklingprozesses, sondern eines anderen physikalischen Formbildungsmechanismus, der als intrinsic curvature driven morphogenesis bezeichnet wird (Goriely und Tabor 1998, McMillen und Goriely 2002). Es bleibt zukünftigen Studien vorbehalten, herauszufinden, welche der gegenwärtig diskutierten Hypothesen zur Biomechanik des Cardiac looping am besten mit der biologischen Wirklichkeit übereinstimmt. 


\section{Zusammenfassung}

Der Prozess der Umformung des geraden embryonalen Herzschlauchs in eine helikal gewundene Herzschleife wird Cardiac looping genannt. Diese Schleifenbildung wird als einer der wesentlichen Formbildungsprozesse des Wirbeltierherzens angesehen, da er die Bauelemente/Segmente des sich entwickelnden Herzens (Sinus venosus, Vorhöfe, Ventrikel, große arterielle Gefäßstämme) annähernd in ihre definitiven topographischen Beziehungen zueinander bringt. Störungen des Cardiac looping führen $\mathrm{zu}$ komplexen angeborenen Herzfehlern mit abnormen Verbindungen zwischen den Segmenten des vierkammerigen Herzens (z. B. Double-outlet right ventricle, Congenitally corrected TGA). Die Herzschleifenbildung läuft bei allen Wirbeltierspezies in ähnlicher Weise ab und führt im Normalfall zur Ausbildung einer linksgewundenen Herzschleife, die allgemein als D-Loop bezeichnet wird, da ihre Ventrikel anfänglich nach rechts verlagert werden. Rechtsgewundene Herzschleifen sind äußerst seltene Ergebnisse des Cardiac looping, die sich z. B. beim Situs inversus finden. Sie werden allgemein als L-Loop bezeichnet, da ihre Ventrikel anfänglich nach links verlagert werden.

Das wissenschaftliche Interesse am Phänomen des Cardiac looping fokussiert sich im Wesentlichen auf zwei Fragen: (1.) Welche Faktoren führen zur helikalen Verformung des embryonalen Herzschlauchs? (2.) Welche Faktoren sind dafür verantwortlich, dass bei allen bisher untersuchten Wirbeltieren während der Embryogenese normalerweise nur D-Loops erzeugt werden?

Während der letzten zwei Jahrzehnte wurde eine Vielzahl an Genen identifiziert, die wichtige Rollen beim Cardiac looping spielen. Die Frage, wie diese genetischen Informationen in mechanische Kräfte übersetzt werden, welche die Formänderungen der Herzschleife bewirken, blieb bisher größtenteils unbeantwortet. Die älteste Hypothese zur Mechanik des Cardiac looping schreibt die Formänderungen der Herzschleife (ventrale Biegung $\rightarrow$ einfache helikale Windung $\rightarrow$ komplexe helikale Windung) Kompressionsbelastungen zu, die aus dem ungleichen Längenwachstum des Herzens und der Perikardhöhle resultieren sollen.

In der vorliegenden Studie wurde die physikalische Plausibilität dieser Hypothese, die ich als wachstumsbedingtes Buckling bezeichne, zum ersten Mal experimentell geprüft. Anhand eines physikalischen Simulationsmodells konnte ich zeigen, dass wachstumsbedingtes Buckling eines geraden elastischen Stabs (Modell des Herzschlauchs) innerhalb einer ihn 
einengenden halbkugeligen Höhle (Modell der Perikardhöhle) eine Abfolge von Formänderungen erzeugen kann, die derjenigen entspricht, die bei der embryonalen Herzschleifenbildung beobachtet wird. Meine Experimente haben weiterhin gezeigt, dass durch Wachstum bedingtes Buckling unter bilateral symmetrischen Bedingungen links- und rechtshändige Helices in einem Zahlenverhältnis von nahezu 1:1 erzeugt. Bereits geringfügige Links- oder Rechtsverschiebungen des caudalen Endes des elastischen Stabs vor Beginn des simulierten Längenwachstums reichten aus, um den Bucklingprozess in eine Richtung zu lenken, bei der es ausschließlich zur Erzeugung von D- bzw. L-Loops kam. Die biologische Relevanz dieser am physikalischen Modell erhobenen Daten wird anhand von Beobachtungen an biologischen Modellen (Embryonen von Zebrafisch, Krallenfrosch, Axolotl, Huhn, Maus) diskutiert. Hierbei komme ich zu folgenden Schlüssen: (1.) Aus ungleichem Längenwachstum des Herzens und der Perikardhöhle resultierende Kompressionsbelastungen des Herzschlauchs dürften wichtige Beiträge zum Cardiac looping leisten. (2.) Asymmetrische Positionierungen des venösen Herzpols könnten diese Kräfte in Richtung einer 100\%igen Erzeugung eines D- bzw. L-Loops lenken. 


\section{Literaturverzeichnis}

Aiello VD, Xavier-Neto J (2006): Full intrauterine development is compatible with Cardiac bifida in humans. Pediatr Cardiol 27, 393-394

Aiello VD, de Morais CF, Ribeiro IG, Sauaia N, Ebaid M (1987): An infant with two "halfhearts" who survived for five days: a clinical and pathological report. Pediatr Cardiol $\underline{8}, 181$ 186

Bayraktar M, Männer J (2014): Cardiac looping may be driven by compressive loads resulting from unequal growth of the heart and pericardial cavity. Observations on a physical simulation model. Front Physiol $\underline{5}, 112$

Bacon RL (1945): Self-differentiation and induction of the heart of Amblystoma. J Exp Zool $\underline{98}, 87-125$

Beloussov LV, Grabovsky VI (2006): Morphomechanics: goals, basic experiments and models. Int J Dev Biol 50, 81-92

Biben C, Harvey RP (1997): Homeodomain factor Nkx2-5 controls left-right asymmetric expression of bHLH gene eHand during murine heart development. Genes Dev 11, 1357-1369

Brade T, Gessert S, Kühl M, Pandur P (2007): The amphibian second heart field: Xenopus islet-1 is required for cardiovasular development. Dev Biol 311, 297-310

Breckenridge RA, Mohun TJ, Amaya E (2001): A role BMP signalling in heart looping morphogenesis in Xenopus. Dev Biol 232, 191-203

Bremer JL (1928): Part I. An interpretation of the development of the heart. Part II. The left aorta of reptiles. Am J Anat $\underline{42}, 307-369$

Butler JK: An Experimental Analysis of Cardiac loop Formation in the Chick. MA thesis, Austin, University of Texas 1952

Chen J-N, van Eeden FJM, Warren KS, Chin A, Nüsslein-Volhard C, Haffter P, Fishman MC (1997): Left-right pattern of cardiac BMP4 may drive asymmetry of the heart in zebrafish. Development $\underline{124}$, 4373-4382

Chin AJ, Tsang M, Weinberg ES (2000): Heart and gut chiralities are controlled independently from initial heart position in the developing zebrafish. Dev Biol 227, 403-421

Choudhry P, Trede NS (2013): DiGeorge syndrome gene tbx1 functions through wnt11r to regulate heart looping and differentiation. PLoS ONE $\underline{8}$, e581455

Copenhaver WM (1926): Experiments on the development of the heart of Amblystoma punctatum. J Exp Zool 43, 321-371

Davis CL (1927): The development of the human heart from its first appearance to the stage found in embryos of twenty paired somites. Contr Embryol Carnegie Inst 19, 245-284 
De Boer BA, van den Berg G, Soufan AT, de Boer PA, Hagoort J, van den Hoff MJ, Moorman AF, Ruijter JM (2012): Measurement and 3D-visualizaion of cell-cycle length using double labelling with two thymidine analogues applied in early heart development. PLoS ONE $\underline{7}$, e47719

DeHaan R (1958): Modification of cell-migration patterns in the early chick embryo. PNAS $\underline{44}, 32-37$

DeHaan R (1959): Cardia bifida and the development of pacemaker function in the early chick heart. Dev Biol 1, 586-602

De Vries PA, Saunders JA de CM (1962): Development of the ventricles and spiral outflow tract of the human heart. Contr Embryol Carnegie Inst 37, 87-114

Doherty JT, Conlon FL, Mack CP, Taylor JM (2010): Focal adhesion kinase is essential for cardiac looping and multichamber heart formation. Genesis $\underline{48}, 492-504$

Ekman G (1925): Experimentelle Beiträge zur Herzentwicklung der Amphibien. Roux Arch Entw Mech Org 106, 320-352

Fales DE (1946): A study of double hearts produced experimentally in embryos of Ambystoma punctatum. J Exp Biol 101, 281-298

Filas BA, Efimov IR, Taber LA (2007): Optical coherence tomography as a tool for measuring morphogenetic deformation of the looping heart. Anat Rec 290, 1057-1068

Flynn ME, Pikalow AS, Kimmelmann RS, Searls RL (1991): The mechanism of cervical flexure formation in the chick. Anat Embryol 184, 411-420

Francis RJB, Christopher A, Devine WA, Ostrovski L, Lo C (2012): Congenital heart disease and the specification of left-right asymmetry. Am J Physiol Heart Circ Physiol 302, H2102$\mathrm{H} 2111$

Fransen ME, Lemanski LF (1988): Myocardial cell relationships during morphogenesis in normal and cardiac lethal mutant axolotls, Ambystoma mexicanum. Am J Anat 183, 245-257

Garrity DM, Childs S, Fishman MC, (2002): The heartstring mutation in zebrafish causes heart/fin Tbx5 deficiency syndrome. Development 129, 4635-4645

Goerttler K (1928): Die Bedeutung der ventrolateralen Mesodermbezirke für die Herzanlage der Amphibienkeime. Anat Anz (Ergänzungsheft) $\underline{66}$, 132-139

Goette A: Die Entwicklungsgeschichte der Unke (Bombinator igneus) als Grundlage einer vergleichenden Morphologie der Wirbelthiere. Voss, Leipzig 1875

Goriely A, Tabor M (1998): Spontaneous helix hand reversal and tendril perversion in climbing plants. Phys Rev Lett $\underline{80}, 1564-1567$

Gräper L (1907): Untersuchungen über die Herzbildung der Vögel. Roux Arch Entw Mech Org $\underline{24}, 375-410$ 
Hill CS, Lemanski LF (1979): Morphological studies on cardiac lethal mutant salamander hearts in organ cultures. J Exp Zool 209, 1-20

His W: Untersuchungen über die erste Anlage des Wirbelthierleibes. Die erste Entwicklung des Hühnchens im Ei. FCW Vogel, Leipzig 1868

Icardo JM, Ojeda JL (1984): Effects of colchicine on the formation and looping of the tubular heart of the embryonic chick. Acta Anat $\underline{119}, 1-9$

Kelly R (2012): The second heart field. Curr Top Dev Biol 100, 33-65

Khodiyar VK, Howe D, Talmud P, Breckenridge R, Lovering RC (2014): From zebrafish jogging genes to mouse and human orthologs: using Gene Ontology to investigate mammalian heart development [v2; ref status]. F 1000Research $\underline{2}, 242$

Kidokoro H, Okabe M, Tamura K (2008): Time-lapse analysis reveals local asymmetric changes in c-looping heart tube. Dev Dyn 237, 3545-3556

Klaus A, Saga Y, Taketo MM, Tzahor E, Birchmeier W (2007): Distinct roles of Wnt/Bcatenin and Bmp signaling during early cardiogenesis. PNAS $\underline{104}$, 18531-18536

Kremnyov SV, Troshina TG, Beloussov LV (2012): Active reinforcement of externally imposed folding in amphibians embryonic tissue. Mech Dev 129, 51-60

Latacha KS, Rémond MC, Ramasubramanian A, Chen AY, Elson EL, Taber LA (2005): Role of actin polymerization in bending of the early heart tube. Dev Dyn 233, 1272-1286

Lepori NG (1967): Research on heart development in chick embryo under normal and experimental conditions. Mon Zool Ital $\underline{1}, 159-183$

Li S, Zhou D, Lu MM, Morrisey EE (2004): Advanced cardiac morphogenesis does not require heart tube fusion. Science $\underline{305}, 1619-1622$

Linask KK, Vanauker M (2007): A role for the cytoskeleton in heart looping. Scientific World J $\underline{7}, 280-298$

Linask KK, Han M, Cai DH, Brauer PR, Maisastry SM (2005): Cardiac morphogenesis: matrix metalloproteinase coordination of cellular mechanisms underlying heart tube formation and directionality of looping. Dev Dyn $\underline{233}, 739-753$

Manasek FJ (1981): Determinants of heart shape in early embryos. Fed Proc 40, 2011-2016

Männer J (2000): Cardiac looping in the chick embryo: a morphological review with special reference to terminological and biomechanical aspects of the looping process. Anat Rec $\underline{259}$, 248-262

Männer J (2004): On rotation, torsion, lateralization and handedness of the embryonic heart loop: new insights from a simulation model for the heart loop of chick embryos. Anat Rec $\underline{278 \mathrm{~A}}, 481-492$

Männer J (2009): The anatomy of cardiac looping: a step towards the understanding of the morphogenesis of several forms of congenital cardiac malformations. Clin Anat 22, 21-35 
Männer J (2013): On the form problem of embryonic heart loops, its geometrical solutions, and a new biophysical concept of cardiac looping. Ann Anat 195, 312-323

Männer J, Seidl W, Steding G (1993): Correlation between the embryonic head flexures and cardiac development. An experimental study in chick embryos. Anat Embryol 188, 269-285

Männer J, Seidl W, Steding G (1995): Formation of the cervical flexure: an experimental study on chick embryos. Acta Anat $\underline{152}, 1-10$

Manning A, McLachlan JC (1990): Looping of chick embryo hearts in vitro. J Anat $\underline{168}$, 257263

McMillen T, Goriely A (2002): Tendril perversion in intrinsically curved rods. J Nonlinear Sci $\underline{12}, 241-281$

Murray HA Jr (1919): The development of the cardiac loop in the rabbit, with especial reference to the bulboventricular groove and origin of the interventricular septum. Am J Anat $\underline{26}, 29-39$

Nadal-Ginard B, Paz Garcia M (1972): The morphologic expression of each cardiac primordium in the chick embryo. J Embryol Morph $\underline{28}, 141-152$

Nerurkar NL, Ramasubramanian A, Taber LA (2006): Morphogenetic adaption of the looping embryonic heart to altered mechanical load. Dev Dyn 235, 1822-1829

Niu Z, Iyer D, Conway SJ, Martin JF, Ivey K, Srivastava D, Nordheim A, Schwartz RJ (2008): Serum response factor orchestrates nascent sarcomerogenesis and silences the biomineralization gene program in the heart. PNAS $\underline{105}, 17824-17829$

Panum PL (1859): Duplicitas cordis bei einem übrigens einfachen Hühner-Embryo. Virchows Arch 16, 39-50

Patten BM (1922): The formation of the cardiac loop in the chick. Am J Anat 30, 373-397

Pieranski P, Baranska J, Skjeltorp A (2004): Tendril perversion - a physical implication of the topological conservation law. Eur J Phys $\underline{30}$, 613-621

Ramasubramanian A, Latacha KS, Benjamin JM, Voronov DA, Ravi A, Taber LA (2006): Computational model for early cardiac looping. Ann Biomech Eng $\underline{34}$, 1355-1369

Ramasubramanian A, Chu-Lagraff QB, Buma T, Chico KT, Carnes ME, Burnett KR, Bradner SA, Gordon SS (2013): On the role of intrinsic and extrinsic forces in early cardiac s-looping. Dev Dyn 242, 801-816

Rawles ME, Williers BH (1934): A study in the localization of organ-forming areas in the chick blastoderm of the head-process stage. Anat Rec $\underline{58}$ (Suppl.), 34

Rémond MC, Fee JA, Elson EL, Taber LA (2006): Myosin-based contraction is not necessary for c-looping in the chick embryo. Anat Embryol 211, 443-454 
Ribeiro I, Kawakami Y, Büscher D, Raya Á, Rodríguez-León J, Morita M, Rodríguez Esteban C, Izpisúa Belmonte JC (2007): Tbx2 and tbx3 regulate the dynamics of cell proliferation during heart remodeling. PLoS One 2 , e398

Risebro I, Smart N, Dupays L, Breckenridge R, Mohun TJ, Riley PR (2006): Hand1 regulates cardiomyocyte proliferation versus differentiation in the developing heart. Development 133 , 4595-4606

Robertson JI (1914): The development of the heart and vascular system of Lepidoserin paradoxa. Q J Microsci Sci $\underline{59}, 53-132$

Schulte HW (1916): The fusion of the cardiac anlages and the formation of the cardiac loop in the cat (felis domestica). Am J Anat 20, 45-72

Stalsberg H (1970): Mechanism of dextral looping of the embryonic heart. Am J Cardiol 25 , 265-271

Stöhr P Jr (1925): Experimentelle Studien an embryonalen Amphibienherzen. III. Über die Entstehung der Herzform. Arch Entwickl Mech Org 106, 409-455

Stöhr P Jr (1926): Zwei neue experimentelle Resultate zur Herzentwicklung bei Amphibien. Arch Entwickl Mech Org 106, 409-455

Taber LA (2006): Biophysical mechanisms of cardiac looping. Int J Dev Biol. 무, 323-332

Taber LA, Voronov DA, Ramasubramanian A (2010): The role of mechanical forces in the torsional component of cardiac looping. Ann NY Acad Sci 1188, 103-110

Tan XC, Forsman B (1995): Buckling of slender string in cylindrical tube under axial load: experimental and theoretical analysis. Experimental Mechanics 35, 55-60

Tandler J: The development of the heart; in: Manual of Human Embryology Vol 2, hrsg. Keibel F, Mall FP; Lippincott Company, Philadelphia, London, 1912, 534-570

van den Berg G, Abu-Issa R, de Boer BA, Hutson MR, de Boer PA, Soufan AT, Ruijter JM, Kirby ML, van den Hoff MJ, Moorman AF (2009): A caudal proliferating growth center contributes to both poles of the forming heart tube. Circ Res 104, 179-188

von Baer KE: Über Entwickelungsgeschichte der Thiere. Beobachtung und Reflexion. Gebr. Bornträger, Königsberg 1828

Voronov DA, Taber LA (2002): Cardiac looping in experimental conditions: effects of extraembryonic forces. Dev Dyn 224, 413-421

Voronov DA, Alford PW, Xu G, Taber LA (2004): The role of mechanical forces in dextral rotation during cardiac looping in the chick embryo. Dev Biol 272, 339-350

Weiss P: Entwicklungsphysiologie der Tiere. Steinkopff, Dresden, Leipzig 1930

Yelbuz TM, Waldo KL, Kuminski DH, Stadt HA, Wolfe RR, Leatherbury L, Kirby ML (2002): Shortened outflow tract leads to altered cardiac looping after neural crest ablation. Circulation 106, 504-510 
Yokoyama T, Copeland NG, Jenkins NA, Montgomery CA, Elder FF, Overbeek PA (1993): Reversal of left-right asymmetry: a situs inversus mutation. Science 260, 679-682

Zamir EA, Srinivasan V, Perrucchio R, Taber LA (2003): Mechanical asymmetry in the chick heart during looping. Ann Biomed Eng 1ㅗ 1327-1336

Zwirner R, Kuhlo B (1964): Die prospektive Potenz der rechten und der linken Herzanlage (ein experimenteller Beitrag zur Asymmetrie des Herzens). Roux Arch Entwickl Mech 155, $511-524$ 


\section{Danksagung}

Herrn Priv.-Doz. Dr. med. Jörg Männer möchte ich herzlich für die Überlassung des Dissertationsthemas und für seine freundliche und intensive Betreuung danken.

Ebenso gilt mein Dank Herrn Hans-Georg Sydow für seine Unterstützung bei der Fotodokumentation meiner Befunde.

Frau Freya Gehrke, Herrn Sebastian Freiseis und Frau Kirby Hielscher danke ich für das ausführliche Korrektorat. 


\section{Lebenslauf}

Am 11.02.1989 wurde ich, Meriç Bayraktar, als erstes und einziges Kind der Schneiderin und zahnärztlichen Prophylaxeassistentin Hülya Bayraktar, geborene Cevlani, und des Zahnarztes Aydin Bayraktar in Istanbul, Türkei geboren.

Von 1995 bis 1999 besuchte ich die Gördeler-Grundschule in Berlin-Charlottenburg. 2001 wechselte ich in die Eosander-Schinkel-Grundschule, die ebenfalls in Berlin-Charlottenburg gelegen ist. Von 2001 bis 2005 besuchte ich die Wald-Oberschule in Berlin-Charlottenburg und wechselte im Jahre 2005 auf das naturwissenschaftliche Oberstufenzentrum Lise Meitner in Berlin-Neukölln. Auf der Lise-Meitner-Schule absolvierte ich am 27.5.2008 mein Abitur.

Im Anschluss leistete ich vom 1. September bis zum 31. Mai meinen Zivildienst an der Charité in Berlin in der Abteilung für Kieferorthopädie, Orthodontie und Kinderzahnmedizin.

2009 begann ich eine Ausbildung zum Zahntechniker bei Thie und Söhne in Berlin, die ich 2010 frühzeitig beendete, um mein Studium der Zahnmedizin an der Georg-AugustUniversität im Sommersemester 2010 aufzunehmen. Seit September 2011 bin ich Doktorand bei Herrn PD Dr. med. Männer im Institut für Anatomie und Embryologie in der AG CardioEmbryologie. Voraussichtlich werde ich das Studium der Zahnmedizin im Sommer 2015 mit der Zahnärztlichen Prüfung beenden. 